Universidad de Lima

Facultad de Ciencias Empresariales y Económicas

Carrera de Contabilidad

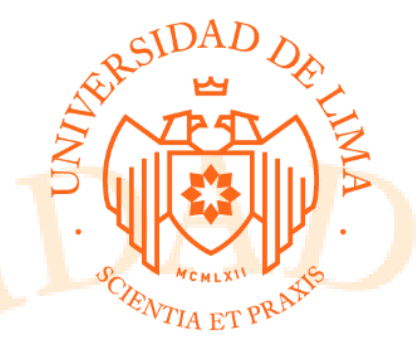

\title{
VALORIZACIÓN DE LA ACCIÓN DE LA COMPAÑÍA CEMENTOS PACASMAYO S.A.A. MEDIANTE EL ANÁLISIS Y PROYECCIÓN DE ESTADOS FINANCIEROS
}

Trabajo de suficiencia profesional para optar el Título Profesional de Contador Público

\author{
Carlos Rivero Villanueva
}

Código 20112269

\section{Asesor}

Julio Catacora Díaz

Noviembre 2018 


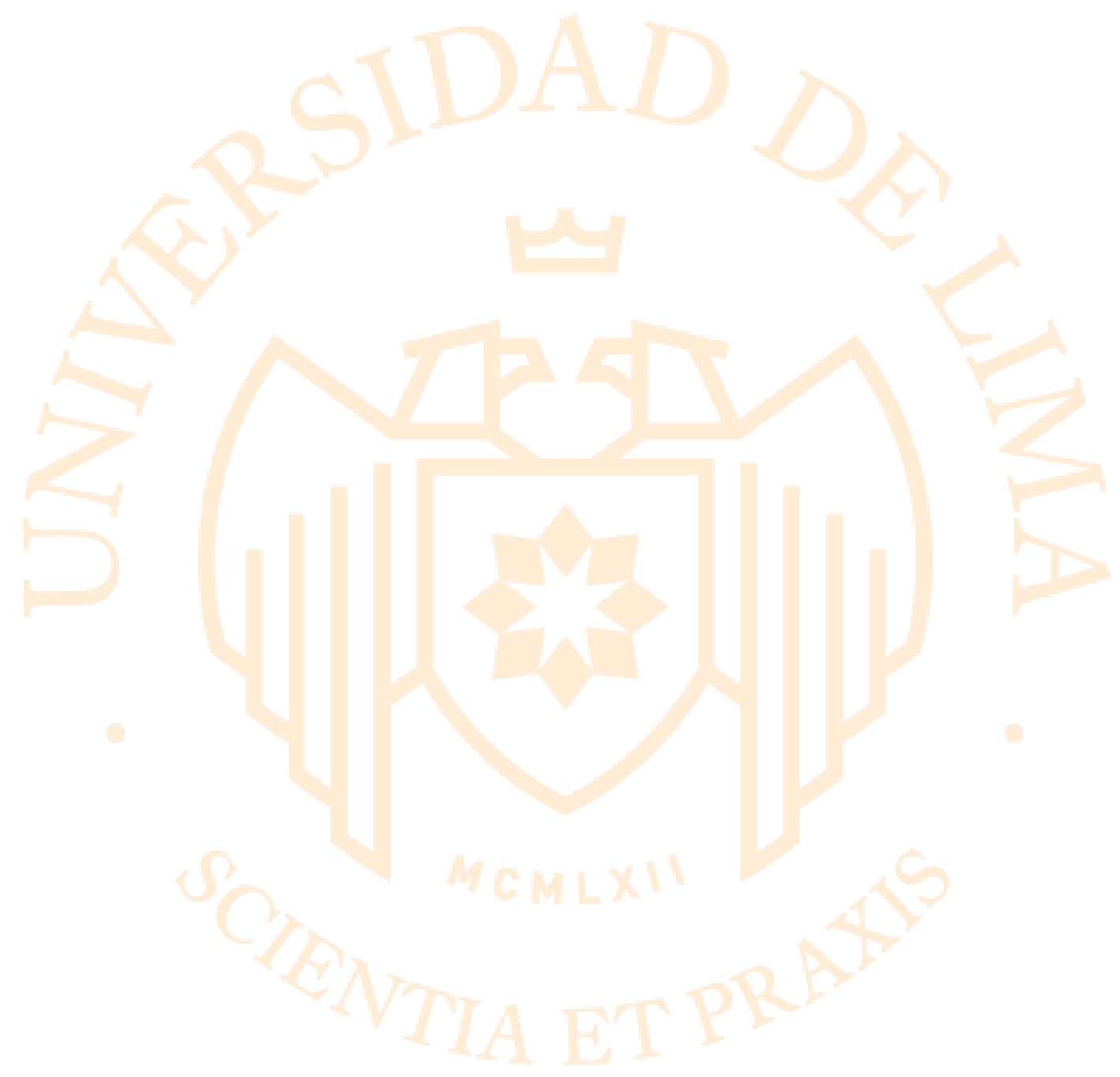




\section{VALORIZATION OF THE SHARES OF THE COMPANY CEMENTOS PACASMAYO S.A.A. THROUGH THE ANALYSIS AND PROJECTION OF FINANCIAL STATEMENTS}




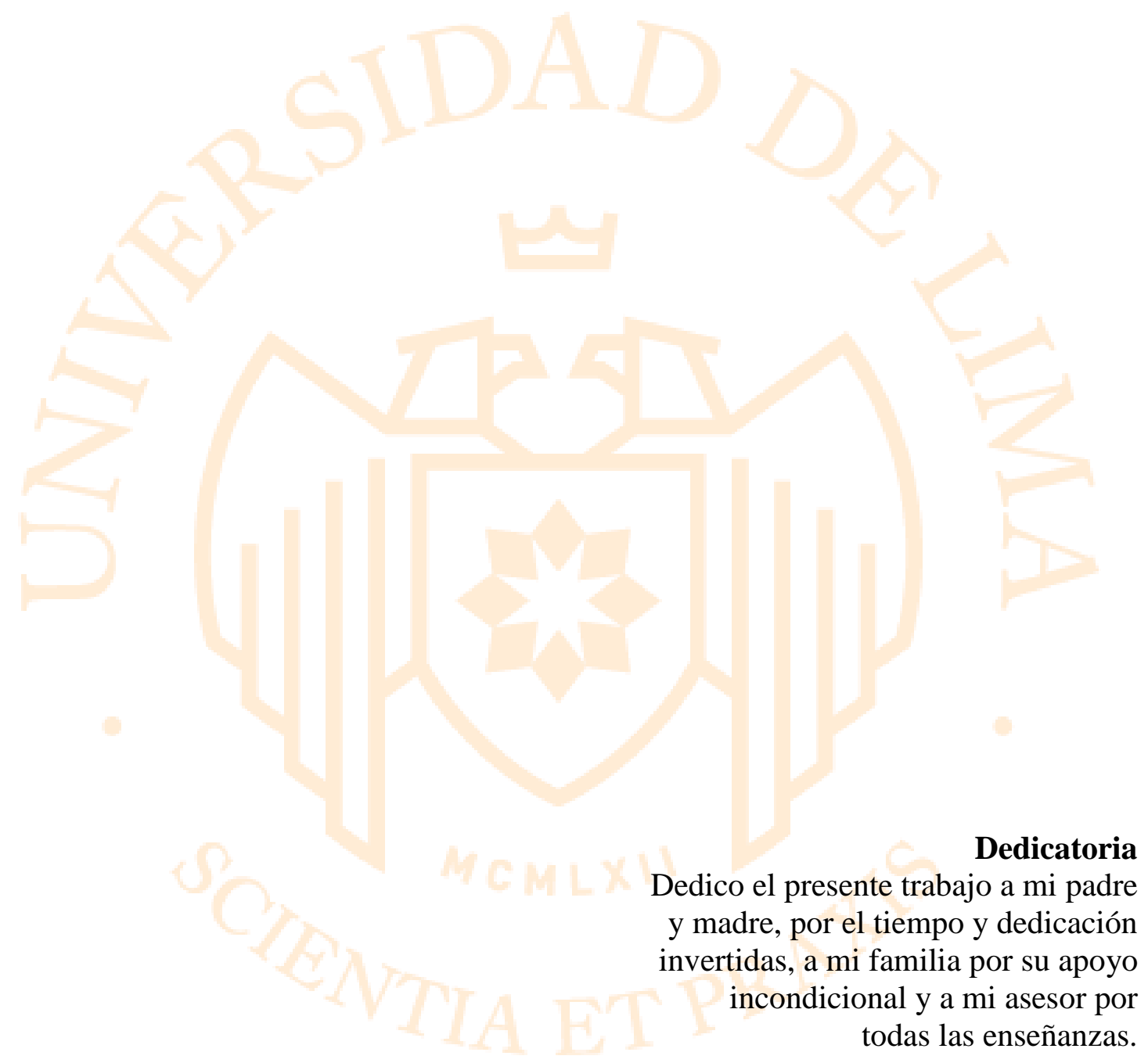




\section{TABLA DE CONTENIDO}

RESUMEN EJECUTIVO_...................................................................1

CAPÍTULO 1: ANTECEDENTES DE LA ENTIDAD ...............................3

1.1 Identificación y actividad económica de la entidad......................................3

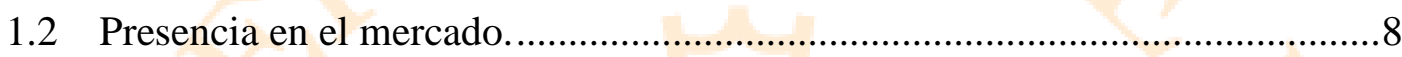

CAPÍTULO 2: DESCRIPCIÓN Y OBJETIVOS DEL TRABAJO DE

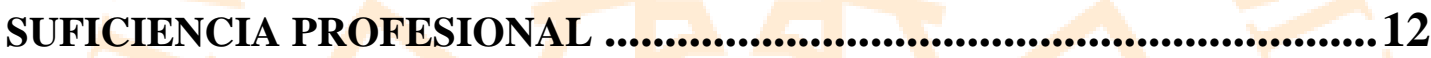

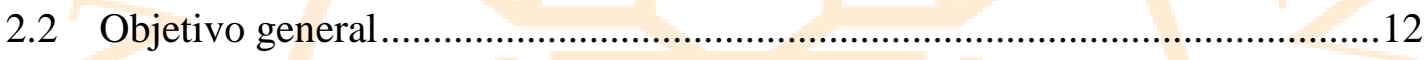

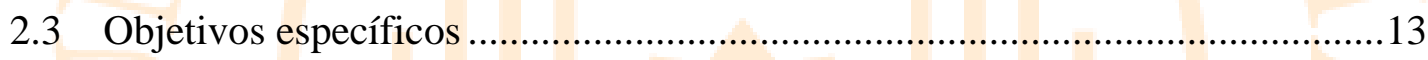

CAPÍTULO 3: MARCO METODOLÓGICO ..........................................14

3.1 Metodología de recolección de la información.............................................14

3.2 Metodología de Análisis de Información.....................................................14

CAPÍTULO 4: ANALISIS DE INFORMACIÓN FINANCIERA.................... 15

4.1 Análisis del Estado de Situación Financiera ...................................................15

4.1.1 Análisis Vertical del Estado de Situación Financiera ….................................16

4.1.2 Análisis Horizontal de Estado de Situación Financiera ..................................19

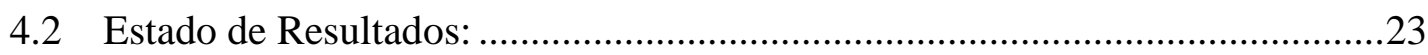

4.2.1 Análisis Vertical de Estado de Resultados .....................................................24

4.2.2 Análisis Horizontal del Estado de Resultados ..............................................33 
4.3 Análisis de ratios financieros:

\section{CAPÍTULO 5: VALORIZACIÓN DE LA ACCIÓN DE LA COMPAÑíA}

CEMENTOS PACASMAYO S.A.A................................32

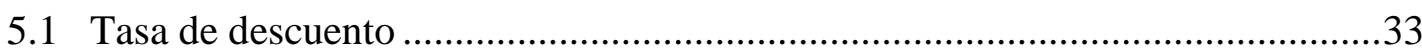

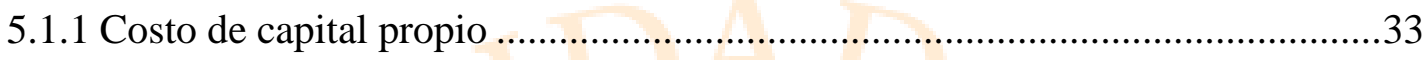

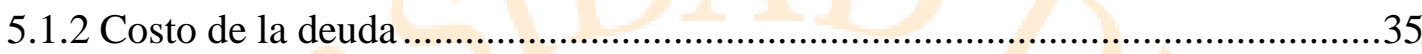

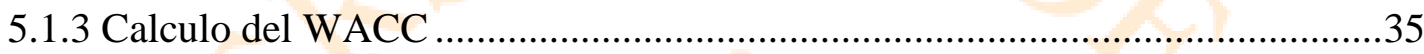

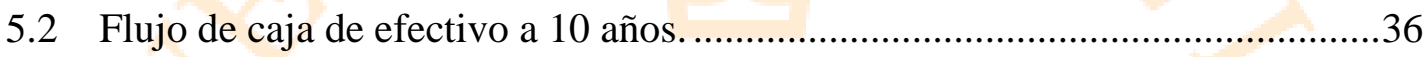

5.2.1 Principales Supuestos para proyectar el flujo de efectivo .............................37

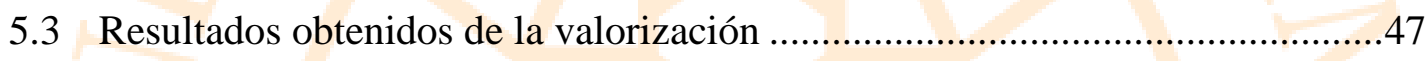

CAPÍTULO 6: CONCLUSIONES Y RECOMENDACIONES ...................40

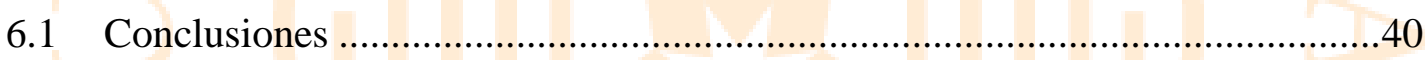

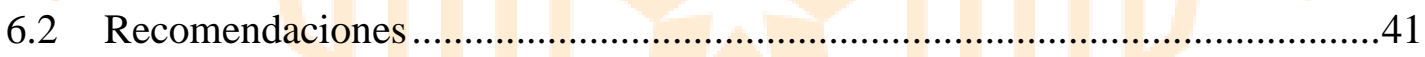

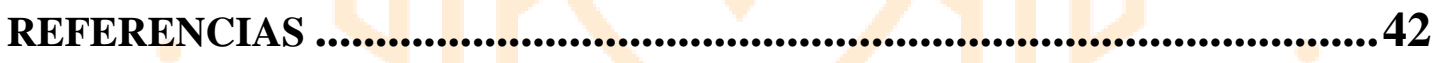

ANEXOS....................................................................46 


\section{ÍNDICE DE TABLAS}

Tabla 1.1 Capacidad, produccion actual y ratio de utilización .................................5

Tabla 1.2 Composición del mercado de cemento ..................................................10

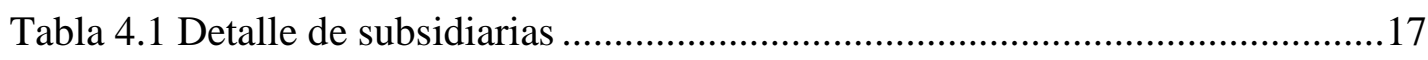

Tabla 4.2 Composicion de las ventas de la Compañía ...........................................24

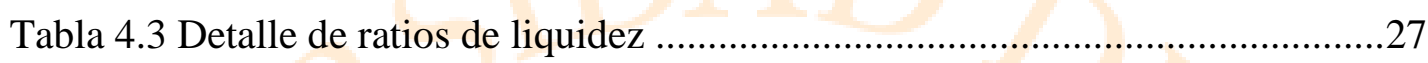

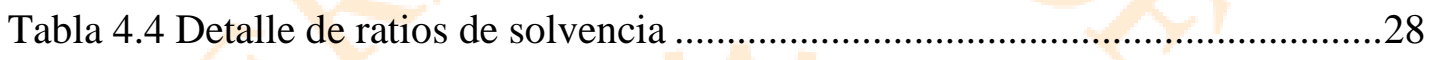

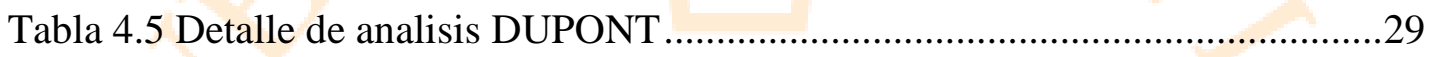

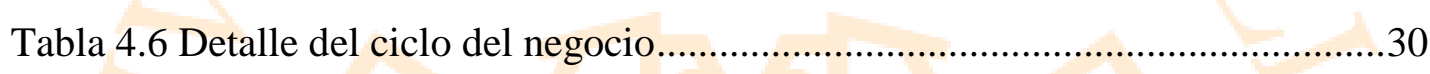

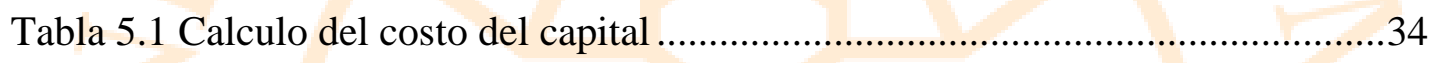

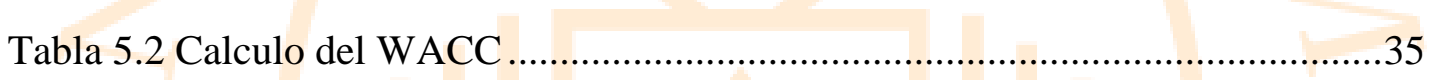

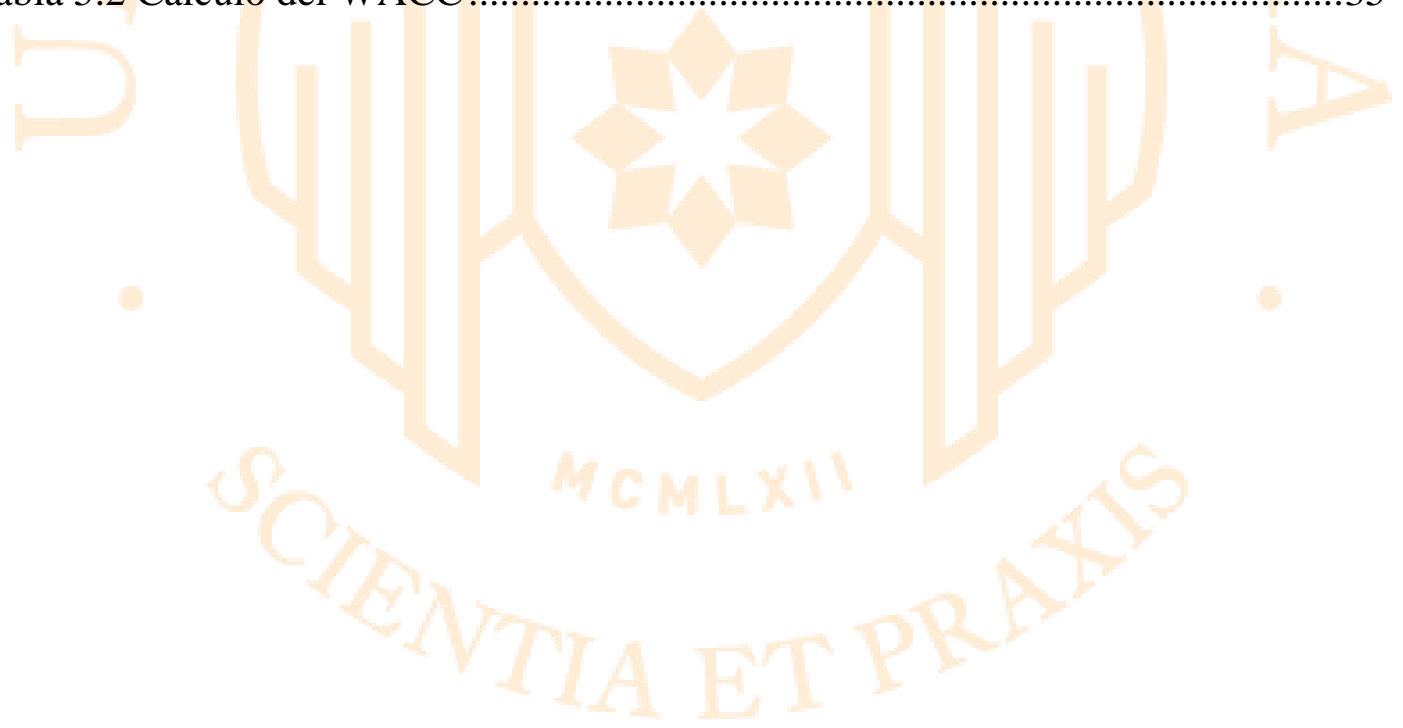




\section{ÍNDICE DE GRÁFICOS}

Grafico 1.1 PBI Nacional y del sector construcción ..............................................8

Grafico 1.2Grandes proyectos por iniciar al final del año 2017 .............................11

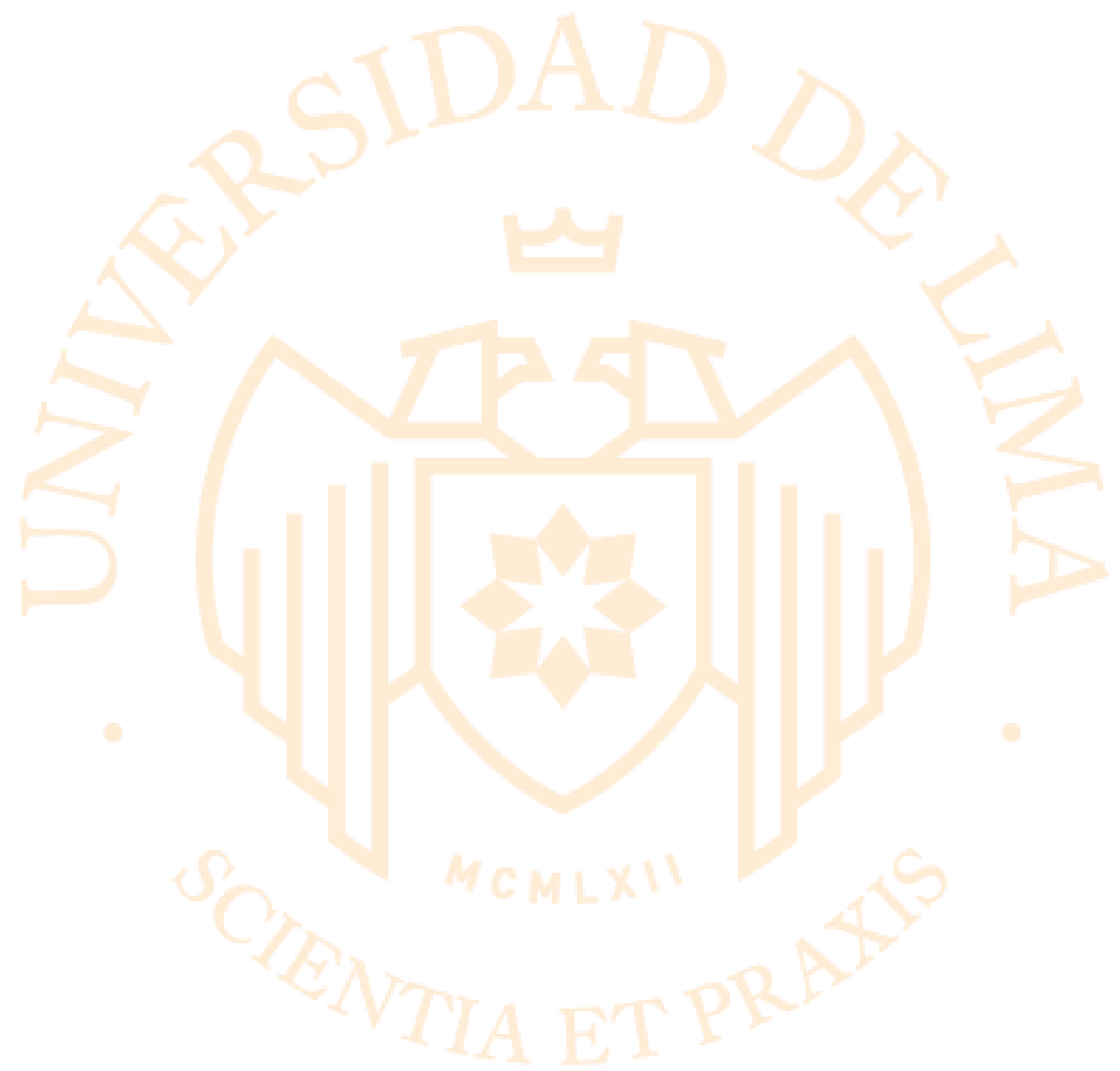

viii 


\section{ÍNDICE DE ANEXOS}

Anexo 1: Proyecto de Reconstrucción con cambios ..................................................47

Anexo 2: Proyección del Estado de Situación Financiera .........................................48

Anexo 3: Proyección del Estado de Resultados .....................................................52

Anexo 4: Proyección de Necesidades Operativas de Fondos (NOF) ........................54

Anexo 5: Análisis de ratios financieros....................................65 


\section{RESUMEN EJECUTIVO}

El presente trabajo de investigación tiene como objetivo determinar la valorización de la Compañía Cementos Pacasmayo S.A.A., bajo la metodología de proyección de flujos de caja descontados, partiendo del análisis de los estados financieros al 31 de diciembre de 2017, y tomando en cuenta los factores económicos y políticos en los que se encuentra actualmente el país.

Compañía Cementos Pacasmayo S.A.A. es una de las empresas cementeras líderes del país, cuya zona geográfica de operación es el norte, zona en la cual mantiene una posición de liderazgo, debido principalmente a la localización de sus plantas y a su amplia red de distribución, la cual es además muy eficiente. Según las cifras de los despachos de cemento a nivel nacional su participación es de $21 \%$ (considerando a su subsidiaria Cementos Selva S.A.).

El crecimiento de los ingresos de la Compañía Cementos Pacasmayo S.A.A. está proyectado considerando el producto bruto interno (PBI) de construcción, debido a que por el proyecto "Reconstrucción con cambios", se estima que el estado invierta aproximadamente S/25,000 millones desde el año 2018 hasta el año 2025 para la reconstrucción del norte del país por los efectos causados por el Fenómeno del Niño. Además se estima que varios proyectos también comiencen su ejecución en los próximos años. 
Luego de aplicar la metodología de valorización, se estima que el valor patrimonial de la Compañía Cementos Pacasmayo S.A.A. a diciembre 2017, es de S/4.423,956 millones, producto del descuento de flujos futuros de la Compañía, basado en diversos supuestos. Debido a esto, se estima que el precio de la acción común es de S/9.43, 15.81\% por encima del valor de mercado reportado al final del año 2017 (S/8.14), por lo que es recomendable que los accionistas que deseen incursionar en el sector construcción inviertan en las acciones de la Compañía Cementos Pacasmayo S.A.A.

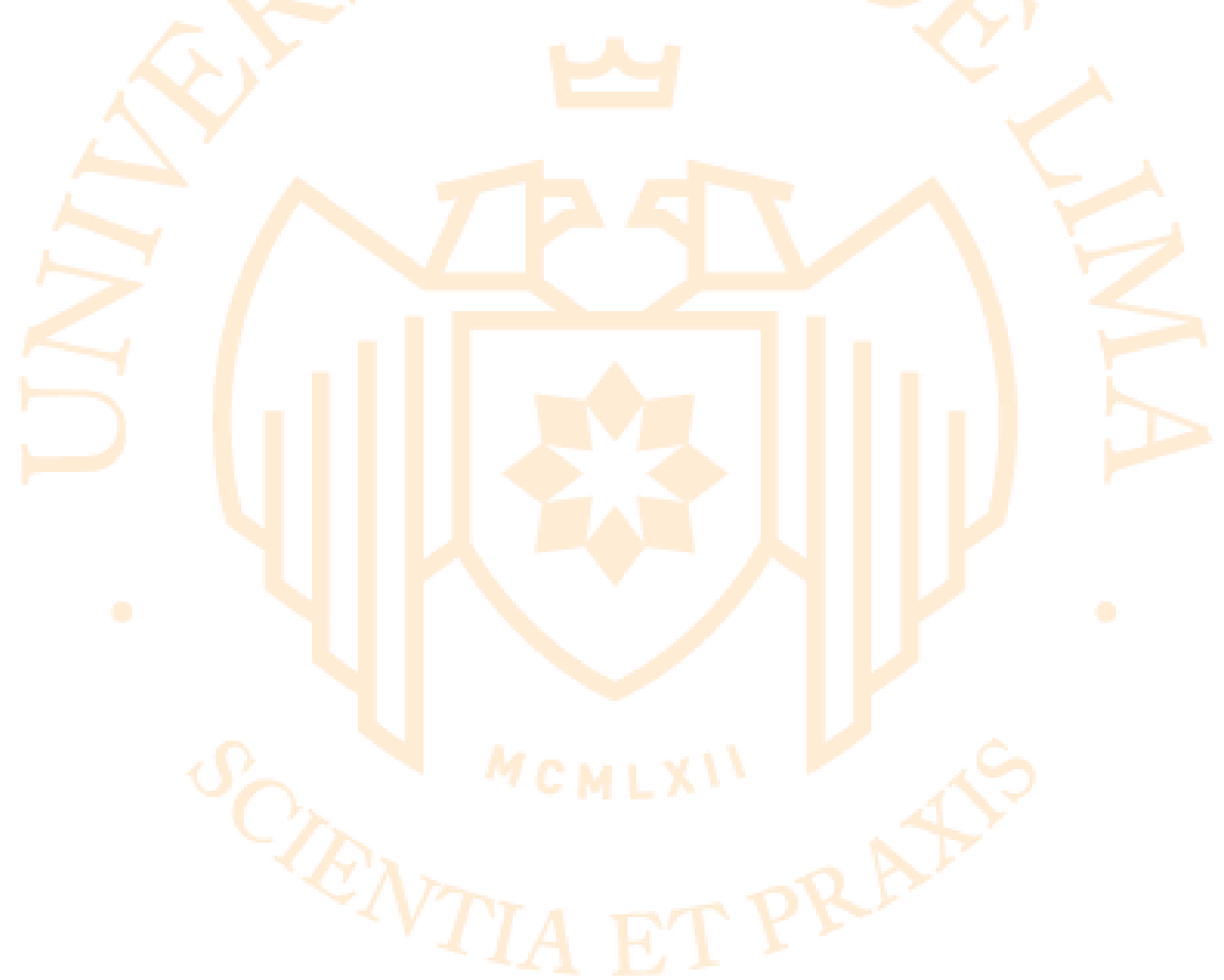




\section{CAPÍTULO 1: ANTECEDENTES DE LA ENTIDAD}

\subsection{Identificación y actividad económica de la entidad.}

Cementos Pacasmayo S.A.A., es una de las empresas cementeras líderes en el Perú. Fue constituida en el año 1957, bajo la Ley General de Sociedades, y es subsidiaria de Inversiones ASPI S.A., la cual tiene una mayor participación en las acciones comunes de la Compañía. La sede principal de la Compañía está ubicada en el distrito de Surco-Lima, y sus principales operaciones de negocio tienen lugar en el norte del país.

Cementos Pacasmayo cotiza en la Bolsa de Valores de Lima desde 1999 y en la Bolsa de Valores de Nueva York desde febrero del 2012. Al 31 de diciembre de 2017, se encuentra conformada por $423,868,449$ acciones comunes totalmente suscritas y pagadas. Del total de estas acciones 70,097,971 se encuentran listadas en la Bolsa Valores de Nueva York y 419,977,479 en la Bolsa de Valores de Lima.

La estructura del accionariado de la Compañía Cementos Pacasmayo S.A.A. se encuentra conformado de la siguiente manera: Inversiones ASPI S.A. con una participación de 50.01\%, JP Morgan Chase Bank, con una participación de 16\%, Fondos de AFP con una participación de $18 \%$; el porcentaje restante lo mantienen otros accionistas minoritarios.

De acuerdo a la Bolsa de valores de Lima (BVL, 2018) explicó que la sociedad tiene por objeto dedicarse a la producción y comercialización de cemento, bloques, 
concreto y cal, en el norte del Perú. Asimismo, la sociedad puede realizar todo tipo de actividades mineras de cateo, prospección, exploración, desarrollo, explotación, comercialización, labor general, beneficio y transporte, así como realizar todas las actividades relacionadas con la prestación del servicio de transporte de mercancías en general y de materiales y residuos peligrosos, incluidos insumos químicos y bienes fiscalizados y celebrar y suscribir todos los actos y contratos convenientes para la consecución de su objeto social

La empresa actualmente cuenta con 2 plantas para la producción, con una capacidad de producción total de 4.5 millones de toneladas métricas de cemento y 2.5 millones de toneladas métricas de Clinker (es la principal materia prima para la producción de cemento y se obtiene producto de la calcinación en de la arcilla con la caliza en un horno). La planta principal se encuentra ubicada en la ciudad de Pacasmayo en la región La Libertad; y, la segunda planta, de mayor capacidad y con tecnología de punta recientemente construida, se ubica en la región Piura.

De acuerdo a la nota de prensa presentada por la Compañía Cementos Pacasmayo S.A.A. (Pacasmayo, 2016), la nueva Planta de Piura inició operaciones en febrero del año 2016, aumentando la capacidad de producción de la Compañía. Además, gracias a la tecnología instalada en la nueva planta, se ha reemplazado el Clinker importado por el Clinker producido, disminuyendo sustantivamente sus costos; además, se viene trasladando la producción de cemento, de plantas menos eficientes a la nueva planta en Piura, lo cual tiene un impacto favorable en los costos, márgenes actuales y futuros de la Compañía. 
A continuación, se muestra el detalle de la capacidad de utilización de las plantas de Piura y Pacasmayo, y un balance de la producción del principal insumo (Clinker) y el principal producto (Cemento) de la Compañía desde el año 2015 al 2017 (en miles de toneladas métricas), de acuerdo a la tabla 1.1

Tabla 1.1

Capacidad, Producción actual y ratio de utilización

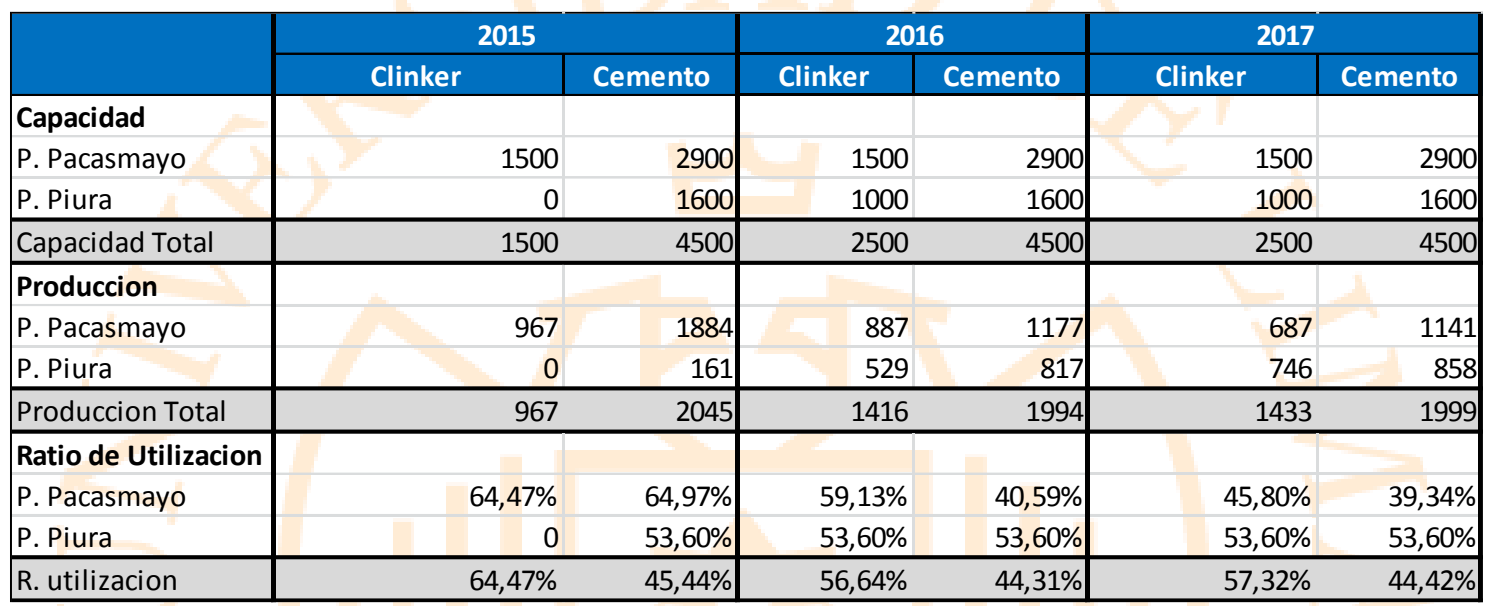

Fuente: Nota de prensa Cementos Pacasmayo al 31 de diciembre de 2017, Elaboración propia.

Cémentos Pacasmayo utiliza como materia prima del cemento el Clinker y la caliza, este último se extrae de las propias canteras de la Compañía concesionadas. Para la planta Pacasmayo se realiza la extracción de la cantera "Acumulación tembladera", ubicada a 60 kilómetros de la planta (se tiene una concesión con un término indefinido para extraer piedra caliza y otros minerales) y para la planta de Piura, se extraen conchas marinas de las canteras de Bayovar 4 y Virrila, ubicadas a 140 y 120 kilómetros de la planta, la cual también mantiene una concesión con término indefinido.

Otros insumos que utiliza la Compañía son el carbón y la electricidad como fuente de energía. En el caso de la electricidad este se obtiene a través de contratos a largo plazo. La empresa estatal Electro Perú abastece a la planta de Pacasmayo y a la planta de Piura. Adicionalmente, la Compañía se abastece de electricidad por su subsidiaria Empresa de 
Transmisión Guadalupe S.A.C. Además, utiliza otros insumos como yeso y diversos aditivos que son abastecidos por proveedores locales.

De acuerdo a ASOCEM (Asociación de Productores de Cemento) (2016), cuyo objetivo es la promoción, desarrollo y protección de la industria de cemento, el proceso de producción del cemento consta de los siguientes pasos:

1. Explotación y extracción de materias primas (caliza): la primera etapa de la fabricación del cemento se inicia con la explotación de los yacimientos de materia prima, en tajo abierto. El material resultante de la voladura es transportado en camiones para su trituración. La trituración de la roca, se realiza en dos partes:

Primero se procesa en una chancadora primaria, del tipo cono que puede reducirse a un tamaño máximo de $1.5 \mathrm{~cm}$ hasta los $25 \mathrm{~cm}$. El material se deposita en un parque de almacenamiento. En seguida, se verifica su composición química, pasa la trituración secundaria, reduciendo su tamaño a $2 \mathrm{~mm}$ aproximadamente. El material triturado se envía a la planta propiamente dicha por cintas transportadoras, depositándose en un parque de materias primas. En algunos casos se efectúa un proceso de prehomogeneización.

2. Molienda de la materia prima: la siguiente etapa comprende la molienda, por molinos de bolas o por prensas de rodillos, que producen un material de gran finura. En este proceso se efectúa la selección de los materiales, de acuerdo al diseño de mezcla previsto, para optimizar el material crudo que ingresará al horno, considerando el cemento de mejores características.

El material molido debe ser homogenizado para garantizar la efectividad del proceso de clinkerización mediante una calidad constante. Este procedimiento se efectúa en silos de homogenización. El material 
resultante constituido por un polvo de gran finura debe presentar una composición química constante.

3. Clinkerización: la harina cruda es introducida mediante un sistema de transporte neumático y debidamente dosificada a un intercambiador de calor por suspensión de gases de varias etapas, sobre la base del cual, se instala un moderno sistema de pre calcinación de la mezcla antes de la entrada al horno rotatorio donde se desarrollan las restantes reacciones físicas y químicas que dan lugar a la formación del Clinker. El intercambio de calor se produce mediante transferencias térmicas por contacto íntimo a temperaturas de 950 a $1,100^{\circ} \mathrm{C}$ en un sistema de 4 a 6 ciclones en cascada, que se encuentran al interior de una torre de concreto armado de varios pisos, con alturas superiores a los cien metros.

El horno es el elemento fundamental para la fabricación del cemento. Está constituido por un tubo cilíndrico de acero con longitudes de 40 a $60 \mathrm{~m}$ y con diámetros de 3 a $6 \mathrm{~m}$, que es revestido interiormente con materiales refractarios, en el horno para la producción del cemento se producen temperaturas de 1500 a $1600^{\circ} \mathrm{C}$, dado que las reacciones de clinkerización se encuentra alrededor de $1450^{\circ} \mathrm{C}$. El Clinker que ingresa al horno de una temperatura de $1200{ }^{\circ} \mathrm{C}$ pasa luego a un proceso de enfriamiento rápido por enfriadores de parrilla. Seguidamente por transportadores metálicos es llevado a una cancha de almacenamiento.

Mediante un proceso de extracción controlada, el Clinker es conducido a la molienda de cemento por molinos de bolas a circuito cerrado o prensas de rodillos con separadores neumáticos que permiten obtener una finura de alta superficie específica. Como último punto, el cemento es transportado por medios neumáticos para depositarse en silos de donde se encuentra listo para ser embolsado y despachado. 


\subsection{Presencia en el mercado.}

El crecimiento económico se ha venido desacelerando desde finales del 2016 debido a una contracción de la demanda interna, principalmente por una menor inversión pública y privada. Sin embargo, se ha visto una moderada recuperación de la demanda interna hacia el segundo y tercer trimestre del 2017, a pesar de ello, el producto bruto interno terminó con un crecimiento de 2,5\%, menor al 4\% registrado en el año 2016 (BCRP, 2018),

La industria cementera está correlacionada al PBI del sector construcción, que creció en 2,2\% en el año 2017 (siendo -3,1\% y -5,9\%, en los años 2016 y 2015, respectivamente) y este a su vez, es influenciado en parte por el PBI nacional, mencionado anteriormente, de acuerdo al grafico 1.1 .

\section{Grafico 1.1}

PBI nacional y del sector construcción

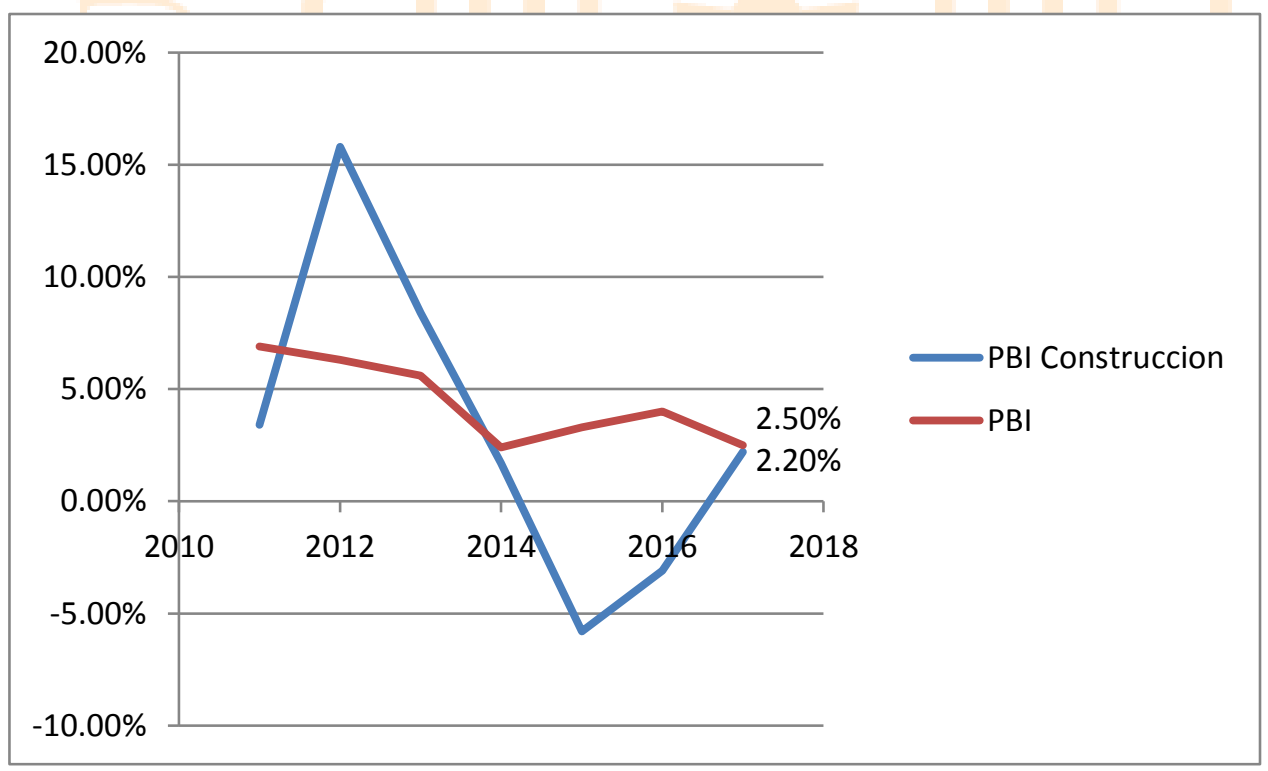

Fuente: Banco Central de Reserva del Perú (2018), Elaboración: Propia

El resultado positivo de 2,2\% del PBI construcción, se debió a la reversión del efecto económico que presentó El Niño Costero a inicios de año, lo cual se refleja en una 
aumento de inversión pública y privada en proyectos de infraestructura en el norte del país en el año 2017, Además, se han aprobado proyectos tales como "El Plan Reconstrucción con Cambios" en setiembre del mismo año, el cual ha planteado contratos de construcción por aproximadamente S/25.6 millones de soles a ser invertidos en el norte del país desde el año 2018 al 2025, para la construcción de infraestructura y asistencia de las regiones afectadas, para mayor detalle ver anexo 1 .

El mercado local de cementeras está compuesto fundamentalmente por cuatro grupos empresariales distribuidos en cinco empresas productoras de cemento: i) UNACEM, que atiende principalmente a las regiones del centro del país y que pertenece al Grupo Rizo-Patrón; ii) Yura, que opera en el sur del Perú y está vinculada al Grupo Rodríguez Banda; iii) Cementos Pacasmayo y Cementos Selva, las cuales atienden principalmente a las regiones del norte del país y pertenecen al Grupo Hochschild; y, iv) Cementos Inca, la cual destina su producción a la zona centro y pertenece a la familia Choy. Adicionalmente, existen importadores de cemento que abastecen básicamente las ciudades de Lima e Iquitos.

De acuerdo al informe de riesgos realizado por Apoyo \& Asociados (2017) a Cementos Pacasmayo, el nivel de competitividad de las cementeras depende, básicamente, de su estructura de costos, la cual está en función del costo de la energía, combustibles, costos de materias primas y de transporte. Sin embargo, las empresas cementeras del país sólo compiten en las zonas límites de su radio de acción debido a su distribución geográfica. Entre las características del sector destacan:

Limitado poder de negociación de los clientes, ante la escasez de una base consolidada de ellos y de empresas que produzcan bienes con mayor valor agregado a base de cemento.

- $\quad$ Reducido poder de negociación de proveedores debido al bajo costo de los principales insumos. 
- $\quad$ Baja rivalidad entre las empresas competidoras debido a la exclusividad geográfica actual.

Alta correlación con la auto-construcción, y con la inversión pública y privada.

- Existencia de barreras de entrada, debido a la alta capacidad instalada, requerimientos de inversión en activo fijo, costo de transporte y necesidad de una red de distribución.

A continuación, se presenta la composición del mercado de cemento en el Perú (en toneladas métricas), de acuerdo a la tabla 1.2:

Tabla 1.2

Composición del mercado del cemento

\begin{tabular}{|c|c|c|c|c|c|}
\hline Región & Compañía & 2015 & 2016 & 2017 & $\begin{array}{c}\text { Participación } \\
\text { (\% 2017) }\end{array}$ \\
\hline \multirow{4}{*}{ Norte } & C. Pacasmayo & 2,022 & 2,004 & 1,981 & $18.53 \%$ \\
\hline & C. Selva & 288 & 281 & 286 & $2.68 \%$ \\
\hline & Importaciones & 12 & - & 69 & $0.65 \%$ \\
\hline & Total & 2,322 & 2,285 & 2,336 & $21.85 \%$ \\
\hline \multirow{4}{*}{ Centro } & UNACEM & 5,546 & 5,110 & 4,993 & $46.71 \%$ \\
\hline & Caliza Inca & 357 & 347 & 387 & $3.62 \%$ \\
\hline & Importaciones & 507 & 490 & 313 & $2.93 \%$ \\
\hline & Total & 6,410 & 5,947 & 5,693 & $53.26 \%$ \\
\hline \multirow{4}{*}{ Sur } & Grupo Yura & 2,480 & 2,645 & 2,618 & $24.49 \%$ \\
\hline & Importaciones & 3 & 18 & 42 & $0.39 \%$ \\
\hline & Total & 2,483 & 2,663 & 2,660 & $24.89 \%$ \\
\hline & Total Nacional & 11,215 & 10,895 & 10,689 & $100.00 \%$ \\
\hline
\end{tabular}

Fuente: Nota de Prensa Cementos Pacasmayo (2018), Elaboración: Propia

De acuerdo a la Nota de Prensa de Cementos Pacasmayo S.A.A. (2018). Los despachos de Cemento disminuyeron en el 2016 pasando de 11,215 a 10,895 miles de toneladas meticas, esto debido a un avance lento de los proyectos de inversión pública y 
a la paralización de algunos proyectos de infraestructura (línea 2 del metro y aeropuerto de Chincheros), lo cual repercute en la ejecución de obras y gasto público. Al cierre de 2017, se observa una disminución de los despachos de cemento producto de los casos de corrupción que afectaron de manera importante a varias constructoras y por ende a varios proyectos que se encontraban en marcha.

Adicionalmente, en la región norte del Perú, donde Cementos Pacasmayo es líder, se están llevando a cabo o están por iniciar algunos grandes proyectos al final del año 2017, los cuales tendrán un efecto positivo en la Compañía, de acuerdo al grafico 1.2:

\section{Grafico 1.2}

Grandes proyectos por iniciar al final del año 2017

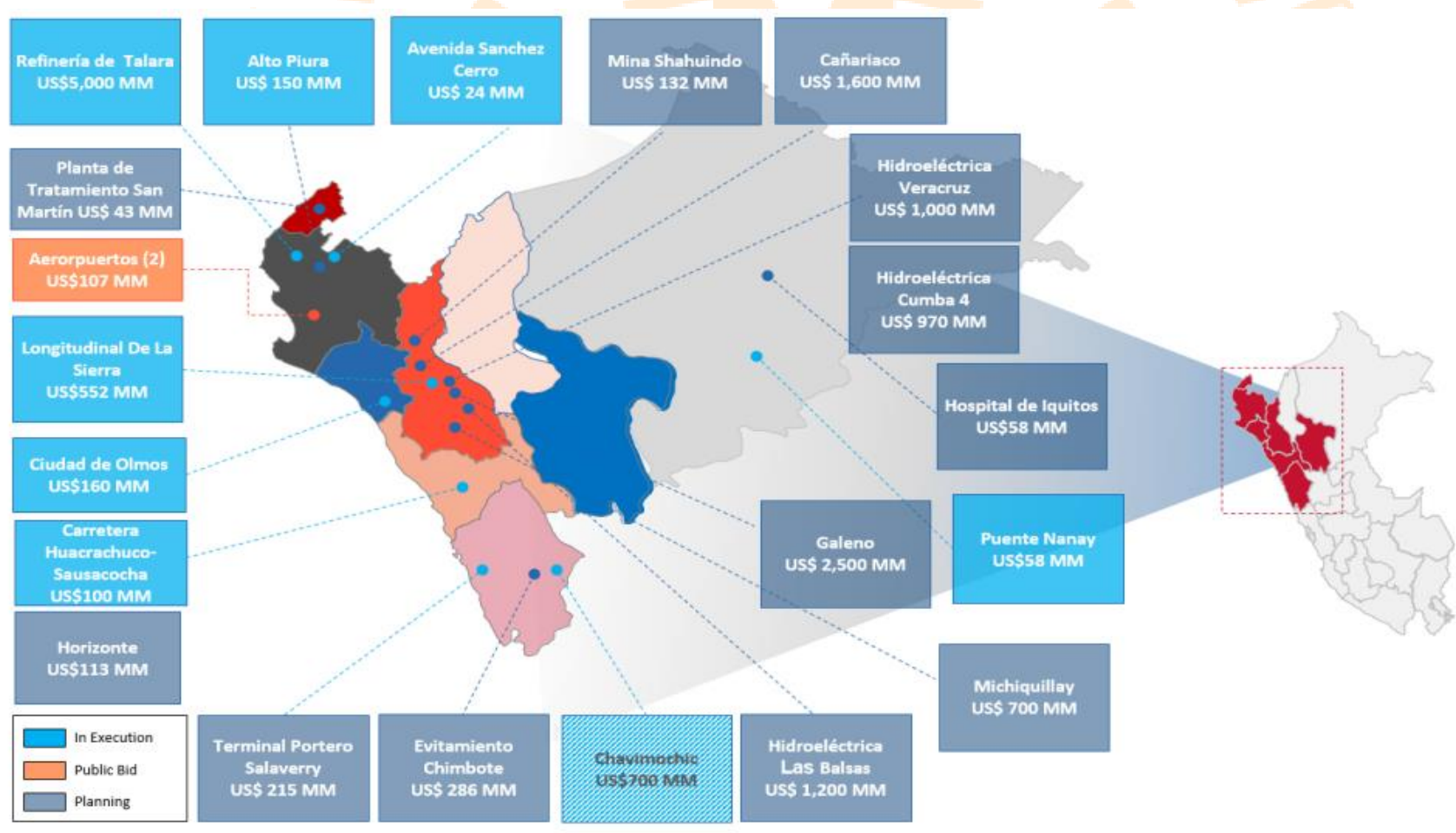

Fuente: Nota de Prensa Cementos Pacasmayo (2017) 


\section{CAPÍTULO 2: DESCRIPCIÓN Y OBJETIVOS DEL TRABAJO DE SUFICIENCIA PROFESIONAL}

\subsection{Descripción del caso de investigación}

En este caso de investigación se realiza la valorización de la acción de la Compañía Cementos Pacasmayo S.A.A. Se inicia la investigación, desde el análisis de la información financiera disponible de los años terminados el 31 de diciembre de 2015,2016 y 2017. Finalmente, se realizará la valorización de la acción de la Compañía, aplicando la metodología de flujo de caja descontado, tomando en cuenta las variables más relevantes analizadas previamente y proyectando los Estados Financieros mediante la identificación de las variables que tengan una mayor relación con los rendimientos en los años posteriores.

\subsection{Objetivo general}

El objetivo del presente trabajo es realizar la valorización de la acción de la Compañía Cementos Pacasmayo S.A.A. mediante la aplicación de la metodología de flujo de caja descontado, analizando previamente la situación presente de la Compañía, utilizando el análisis de ratios, para luego desarrollar un modelo de proyección de estados financieros para plantear un flujo de caja descontado, valorizando la Compañía y su acción, para que los accionistas puedan tomar mejores decisiones de inversión. 


\subsection{Objetivos específicos}

a) Analizar la información financiera (Estado de situación financiera y Estado de resultados) de la Compañía Cementos Pacasmayo S.A.A. desde el año 2015 al 2017, mediante un análisis horizontal, vertical, evaluando las principales variaciones, además de un análisis de ratios financieros.

b) Identificar los supuestos más significativos y calcular una tasa de descuento necesaria para descontar los flujos de caja futuros de la Compañía Cementos Pacasmayo S.A.A., por los años del 2018 al 2027.

c) Valorizar la acción de la Compañía Cementos Pacasmayo S.A.A. aplicando el método de flujo de caja descontado, tomando en cuenta, la coyuntura del tiempo y demás variables analizadas y recomendar a los inversionistas si es apropiado vender, comprar o mantener la acción. 


\section{CAPÍTULO 3: MARCO METODOLÓGICO}

\subsection{Metodología de recolección de la información.}

De acuerdo a Mario Bunge (2004), la metodología de investigación se considera y se define como la disciplina que elabora, sistematiza y evalúa los procedimientos, para la búsqueda de datos y la construcción del conocimiento científico.

Para la metodología de recolección de información en el presente trabajo de investigación se utilizarán diversas páginas webs, Estados Financieros, -informes de clasificadoras de riesgo, libros, notas de prensa, memorias, entre otros.

\subsection{Metodología de Análisis de Información}

En cuanto a la metodología de Análisis de información se utilizará:

- $\quad$ Análisis Vertical

- $\quad$ Análisis Horizontal

- $\quad$ Análisis de los ratios más significativos

Además, para realizar la valorización de la acción de Cementos Pacasmayo se utilizará el método de descuento de flujos de efectivo. 


\section{CAPÍTULO 4: ANÁLISIS DE INFORMACIÓN FINANCIERA}

En el caso del análisis de la información financiera. ésta se ha realizado sobre el estado de situación financiera Separado de la Compañía Cementos Pacasmayo S.A.A. al 31 de diciembre de los años 2017,2016 y 2015, esto debido principalmente a que la Compañía Cementos Pacasmayo S.A.A. representa aproximadamente el $81 \%$ y el $95 \%$ del total de activos y pasivos respectivamente, a nivel consolidado. Además, en el caso de las ventas de la Compañía, estas se realizan a través de las ventas que le realiza la Compañía Cementos Pacasmayo S.A.A. a su subsidiaria Distribuidora Norte Pacasmayo S.A. (debido a que es la distribuidora de la Compañía), sin embargo sus demás subsidiarias no realizan ventas significativas, por lo que se ha realizado el análisis sobre el estado de resultados Separado de Compañía Cementos Pacasmayo S.A.A. de los años 2017, 2016 y 2015.

\subsection{Análisis del Estado de Situación Financiera}

A continuación se presenta el Estado de Situación Financiera Separado de la Compañía Cementos Pacasmayo S.A.A. y sus correspondientes análisis vertical y horizontal, para detallar la composición y variaciones de las principales cifras de la Compañía entre el 31 de diciembre de 2015 al 2017: 


\subsubsection{Análisis Vertical del Estado de Situación Financiera (en miles de soles):}

\begin{tabular}{|c|c|c|c|c|c|c|}
\hline & $\begin{array}{c}\text { Al31 de } \\
\text { diciembre de } \\
2015\end{array}$ & $\begin{array}{l}\text { Analisis } \\
\text { Vertical }\end{array}$ & $\begin{array}{c}\text { Al31 de } \\
\text { diciembre de } \\
2016\end{array}$ & $\begin{array}{l}\text { Analisis } \\
\text { Vertical }\end{array}$ & $\begin{array}{c}\text { Al31 de } \\
\text { Diciembre de } \\
2017 \\
\end{array}$ & $\begin{array}{l}\text { Analisis } \\
\text { Vertical }\end{array}$ \\
\hline & $\mathrm{S} /(000)$ & & $\mathrm{S} /(000)$ & & $\mathrm{S} /(000)$ & \\
\hline \multicolumn{7}{|l|}{ Activos } \\
\hline \multicolumn{7}{|l|}{ Activos corrientes } \\
\hline Efectivo y equivalentes de efectivo & 101,084 & $3.12 \%$ & 43,004 & $1.37 \%$ & 28,823 & $1.05 \%$ \\
\hline $\begin{array}{l}\text { Cuentas por cobrar comerciales y diversas, a } \\
\text { terceros y de relacionadas, neto }\end{array}$ & 147,632 & $4.56 \%$ & 89,136 & $2.83 \%$ & 119,774 & $4.35 \%$ \\
\hline Pagos a cuenta de impuesto a la renta & 29,890 & $0.92 \%$ & 38,554 & $1.22 \%$ & 14,984 & $0.54 \%$ \\
\hline Existencias, neto & 252,650 & $7.81 \%$ & 299,383 & $9.51 \%$ & 324,212 & $11.78 \%(\mathrm{~A})$ \\
\hline Gastos pagados por anticipado & $\quad 3,001$ & $0.09 \%$ & 4,346 & $0.14 \%$ & 1,771 & $0.06 \%$ \\
\hline Total activos corrientes & 534,257 & $16.51 \%$ & 474,423 & $15.07 \%$ & 489,564 & $17.80 \%$ \\
\hline Activos mantenidos para la & & $0.00 \%$ & 234,195 & $7.44 \%$ & - & $0.00 \%$ \\
\hline \multicolumn{7}{|l|}{ Activos no corrientes } \\
\hline Cuentas por cobrar diversas a terceros, no corriente & 4,278 & $0.13 \%$ & 7,899 & $0.25 \%$ & 3,221 & $0.12 \%$ \\
\hline Gastos pagados por anticipado & - & $0.00 \%$ & 724 & $0.02 \%$ & 533 & $0.02 \%$ \\
\hline Inversiones financieras disponibles para la venta & 436 & $0.01 \%$ & 657 & $0.02 \%$ & 21,206 & $0.77 \%$ \\
\hline Otros instrumentos financieros & 124,770 & $3.86 \%$ & 69,912 & $2.22 \%$ & 489 & $0.02 \%$ \\
\hline Propiedad, planta y equipo, neto & $1,915,531$ & $59.20 \%$ & $1,925,840$ & $61.17 \%$ & $1,857,408$ & $67.52 \%(B)$ \\
\hline Intangibles & 7,872 & $0.24 \%$ & 7,811 & $0.25 \%$ & 10,309 & $0.37 \%$ \\
\hline Inversiones en Subsidiarias & 648,765 & $20.05 \%$ & 426,942 & $13.56 \%$ & 368,337 & $13.39 \%(C)$ \\
\hline Total activos no corrientes & $2,701,652$ & $83.49 \%$ & $2,439,785$ & $77.49 \%$ & $2,261,503$ & $82.20 \%$ \\
\hline Total de activos & $3,235,909$ & $100.00 \%$ & $3,148,403$ & $100.00 \%$ & $2,751,067$ & $100.00 \%$ \\
\hline \multicolumn{7}{|l|}{ Pasivos y patrimonio } \\
\hline Pasivo corriente & & & & & & \\
\hline Cuentas por pagar comerciales y diversas & 121,819 & $3.76 \%$ & 114,720 & $3.64 \%$ & 138,851 & $5.05 \%$ \\
\hline Provisiones & 21,728 & $0.67 \%$ & 22,335 & $0.71 \%$ & 17,062 & $0.62 \%$ \\
\hline Total pasivo corriente & 143,547 & $4.44 \%$ & 137,055 & $4.35 \%$ & 155,913 & $5.67 \%$ \\
\hline \multicolumn{7}{|l|}{ Pasivo no corriente } \\
\hline Obligaciones financieras & $1,012,406$ & $31.29 \%$ & 998,148 & $31.70 \%$ & 965,290 & $35.09 \%(D)$ \\
\hline Provisiones no corrientes & 32,638 & $1.01 \%$ & 22,042 & $0.70 \%$ & 27,613 & $1.00 \%$ \\
\hline Pasivo por impuesto a la renta diferido & 104,264 & $3.22 \%$ & 123,718 & $3.93 \%$ & 95,691 & $3.48 \%$ \\
\hline Total pasivos no corrientes & $1,149,308$ & $35.52 \%$ & $1,143,908$ & $36.33 \%$ & $1,088,594$ & $39.57 \%$ \\
\hline Total de pasivos & $1,292,855$ & $39.95 \%$ & $1,280,963$ & $40.69 \%$ & $1,244,507$ & $45.24 \%$ \\
\hline \multicolumn{7}{|l|}{ Patrimonio } \\
\hline Capital social & 531,461 & $16.42 \%$ & 531,461 & $16.88 \%$ & 423,868 & $15.41 \%(E)$ \\
\hline Acciones de inversión & 50,503 & $1.56 \%$ & 50,503 & $1.60 \%$ & 40,279 & $1.46 \%$ \\
\hline Acciones en tesorería & $-108,248$ & $-3.35 \%$ & $-108,248$ & $-3.44 \%$ & $-119,005$ & $-4.33 \%$ \\
\hline Capital adicional & 553,466 & $17.10 \%$ & 545,165 & $17.32 \%$ & 432,779 & $15.73 \%(F)$ \\
\hline Reserva legal & & $5.45 \%$ & 188,075 & $5.97 \%$ & 160,686 & $5.84 \%$ \\
\hline & & $0.36 \%$ & & & & \\
\hline Otros resultados integrales acumulados & 11,649 & 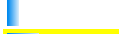 & $-16,602$ & $-0.53 \%$ & $-43,699$ & $-1.59 \%$ \\
\hline Resultados acumulados & 727,765 & $22.49 \%$ & 677,086 & $21.51 \%$ & 611,652 & $22.23 \%(\mathrm{G})$ \\
\hline Total Patrimonio & $1,943,054$ & $60.05 \%$ & $1,867,440$ & $59.31 \%$ & $1,506,560$ & $54.76 \%$ \\
\hline Total pasivos y patrimonio & $3,235,909$ & $100.00 \%$ & $3,148,403$ & $100.00 \%$ & $2,751,067$ & $100.00 \%$ \\
\hline
\end{tabular}

Fuente: Informes Separados de Cementos Pacasmayo S.A.A 2017-2016, 2016-2015 
(A) Al ser una empresa Industrial (productora de cemento y cal) la Compañía mantiene una parte considerable de su activo en las existencias, debido a que aquí se encuentran las materias primas, productos en proceso, repuestos y suministros diversos.

(B) Los activos fijos de la Compañía están compuestos principalmente por edificios, construcciones y maquinaria que se encuentran en las plantas de Pacasmayo y Piura.

(C) Este rubro está compuesto por las siguientes subsidiarias, de acuerdo a la tabla 4.1:

Tabla 4.1

Detalle de subsidiarias

Fosfatos del pacifico

Cementos Selva

Distribuidora Norte Pacasmayo

\section{Empresa de \\ Transmisión \\ Guadalupe \\ Salmueras \\ Sudamericanas}

Calizas del Norte

Otros

\begin{tabular}{|c|c|c|c|}
\hline Actividad & 2015 & 2016 & 2017 \\
\hline $\begin{array}{l}\text { Actividades de exploración y } \\
\text { explotación minera }\end{array}$ & 213,062 & - & - \\
\hline $\begin{array}{l}\text { Producción y comercialización de } \\
\text { cemento y otros materiales de } \\
\text { construcción afines }\end{array}$ & 210,617 & 223,915 & 208,860 \\
\hline $\begin{array}{l}\text { Producción de concreto, bloques y } \\
\text { ladrillos; así como comercialización de } \\
\text { cemento, cal, fierro de construcción y } \\
\text { diversos artículos de ferretería. }\end{array}$ & 106,969 & 118,434 & 117,713 \\
\hline $\begin{array}{l}\text { Servicios de transmisión de energía a la } \\
\text { Compañía. }\end{array}$ & 48,111 & 48,615 & 40,739 \\
\hline $\begin{array}{l}\text { Actividades de exploración y } \\
\text { explotación minera. }\end{array}$ & 34,064 & 35,412 & 439 \\
\hline \multirow[t]{2}{*}{$\begin{array}{l}\text { Actividades de cateo, prospección, } \\
\text { desarrollo, explotación y } \\
\text { comercialización y transporte de } \\
\text { mercancías }\end{array}$} & 35,450 & - & 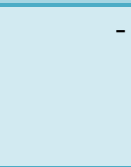 \\
\hline & 492 & 566 & 586 \\
\hline Total & 648,765 & 426,942 & $\mathbf{3 6 8 , 3 3 7}$ \\
\hline
\end{tabular}

Fuente: Informes Separados de Cementos Pacasmayo S.A.A 2017-2016, 2016-2015, Elaboración: Propia 
(D) Este rubro está compuesto por los bonos corporativos de la Compañía, los cuales fueron aprobados por la Junta General de Accionistas celebrada el 7 de enero de 2013. Por ende, el 1 de febrero de 2013, la Compañía emitió bonos corporativos con un valor nominal de US\$300,000,000 con un pago de cupones semestrales a una tasa de interés anual nominal de $4.50 \%$ y vencimiento en 10 años desde su fecha de emisión, obteniendo ingresos totales netos de US\$293,646,000 (S/762,067,000).

(E) En el año 2017 el Capital Social de la Compañía está compuesto por 423,868,449 acciones comunes íntegramente suscritas y pagadas, con un valor nominal de un Sol por acción, de las cuales 70,097,971 están listadas en la Bolsa de Valores de Nueva York y 353,770,478 en la Bolsa de Valores de Lima.

En los años 2016 y 2015 el Capital Social de la Compañía está compuesto por 531,461,479 acciones comunes íntegramente suscritas y pagadas, con un valor nominal de un Sol por acción, de las cuales 111,484,000 estaban listadas en la Bolsa de Valores de Nueva York y 419,977,479 en la Bolsa de Valores de Lima.

(F) El Capital Adicional de la Compañía está compuesto por 111,484,000 acciones comunes y 928,000 acciones de inversión correspondientes a la oferta pública de acciones de depósito americanas (ADS) registradas en la Bolsa de Valores de Nueva York y la Bolsa de Valores de Lima en el año 2012. Este importe corresponde al excedente de la recaudación total obtenida en esta transacción en relación al valor nominal de dichas acciones.

(G) En esta partida se encuentran todos los resultados acumulados que se han obtenido producto de la actividad económica de la Compañía en años anteriores. 


\subsubsection{Análisis Horizontal de Estado de Situación Financiera (en miles de soles):}
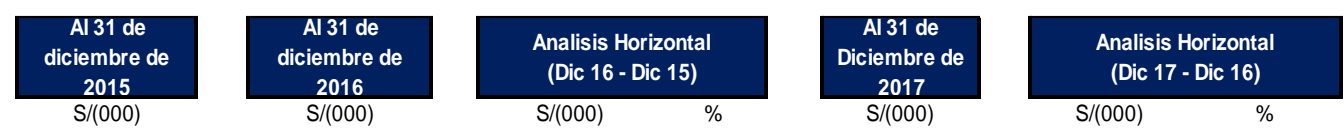

\author{
Activos corrientes \\ Efectivo y equivalentes de efectivo \\ Cuentas por cobrar comerciales y diversas, a \\ terceros y de relacionadas, neto \\ Pagos a cuenta de impuesto a la renta \\ Existencias, neto \\ Gastos pagados por anticipado \\ Total activos corrientes
}

Activos mantenidos para la distribucion
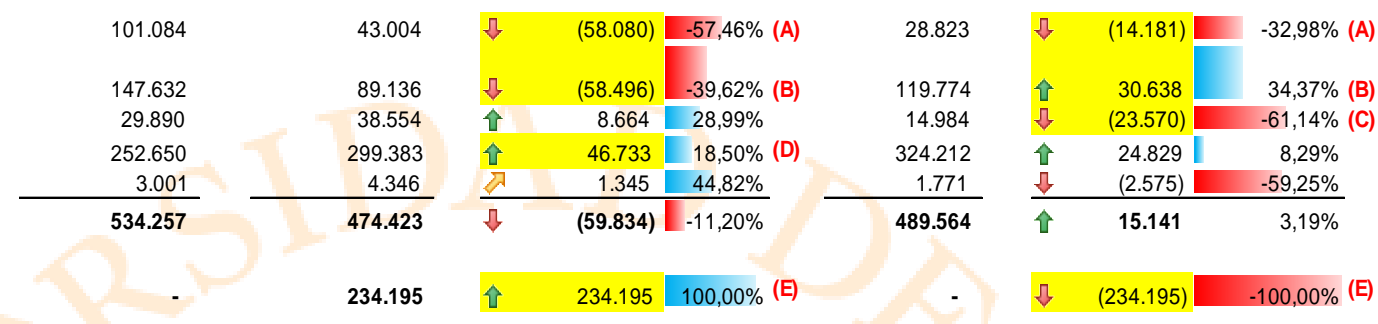

Activos no corrientes

Cuentas por cobrar diversas a terceros, no corriente

Gastos pagados por anticipado

Inversiones financieras disponibles para la venta

Otros instrumentos financieros

Propiedad, planta y equipo, neto

Intangibles

Inversiones en Subsidiarias

Total activos no corrientes

Total de activos

Pasivos y patrimonio

Pasivo corriente

Cuentas por pagar comerciales y diversas

Provisiones

Total pasivo corriente

Pasivo no corriente

Obligaciones financieras

Provisiones no corrientes

Pasivo por impuesto a la renta diferido

Total pasivos no corrientes

Total de pasivos

Patrimonio

Capital social

Acciones de inversión

Acciones en tesorería

Capital adicional

Reserva legal

Otros resultados integrales acumulados Resultados acumulados

Total Patrimonio

Total pasivos y patrimonio

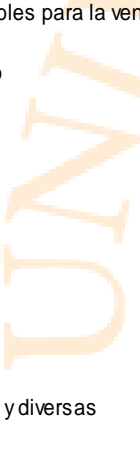

4.278

$-\frac{-}{436}$

436
124.770
1.915 .531

1.915 .531

648.765

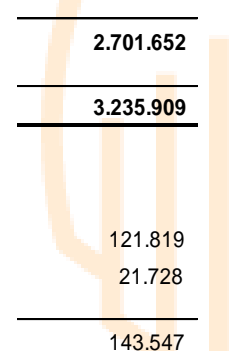

43.547

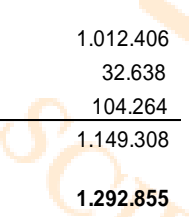

234.195

i $\quad 234.195 \quad 100,00 \%$ (E)
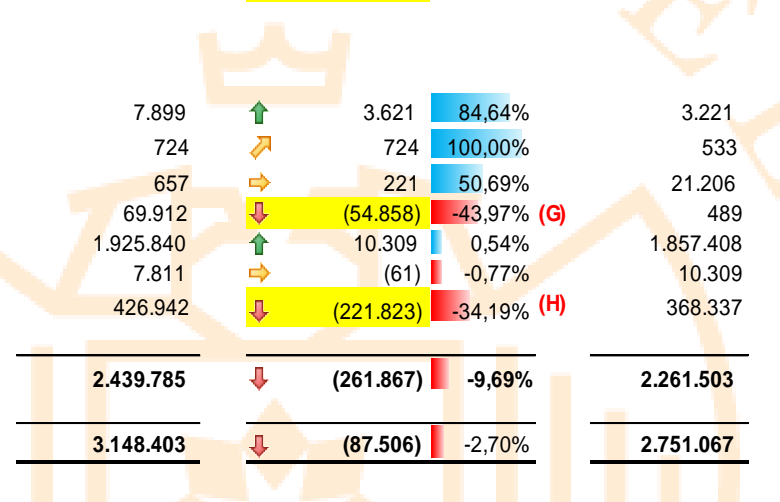

3.221

533

21.206

489

1.857 .408

10.309

368.337

2.261 .503

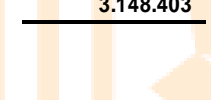

114.720

3
-27

$(7.099)-5,83 \%$

22.335
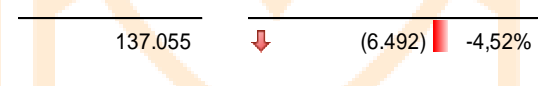

138.851

17.062

155.913
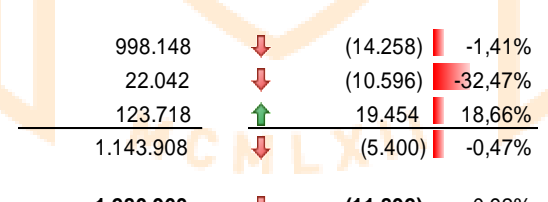

$\begin{array}{r}965.290 \\ 27.613 \\ 95.691 \\ \hline 1.088 .594 \\ \hline\end{array}$

1.244 .507

ป (11.892) $-0,92 \%$

50.503

50.503

$-108.248$

553.466

176.458

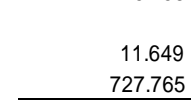

3.235 .909
423.868

40.279

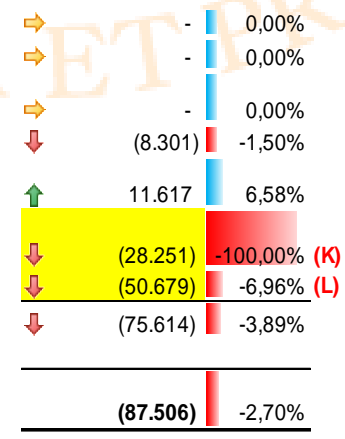

119.005

432.779

160.686

$-43.699$

611.652

1.506 .560

2.751 .067

\begin{tabular}{|c|c|c|}
\hline$\sqrt{7}$ & (4.678) & $-59,22 \%$ \\
\hline$\Rightarrow$ & (191) & $-26,38 \%$ \\
\hline & $\begin{array}{r}20.549 \\
(69.423)\end{array}$ & $\begin{array}{r}100,00 \%(F) \\
-99,30 \%(G)\end{array}$ \\
\hline & (68.432) I & $-3,55 \%$ \\
\hline & 2.498 & $31,98 \%$ \\
\hline & (58.605) & $-13,73 \%(H)$ \\
\hline & (178.282) & $-7,31 \%$ \\
\hline$\sqrt{2}$ & (163.141) & $-5,18 \%$ \\
\hline
\end{tabular}

1) 24.131 ㄴ $21,03 \%$ (I)

ת $\quad-23,61 \%$

\begin{tabular}{ll}
\hline 个 18.858 & $13,76 \%$
\end{tabular}

ᄀ (32.858) | - $1,29 \%$

个 5.571 - $25,27 \%$

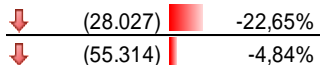

ป $(36.456) \quad-2,85 \%$

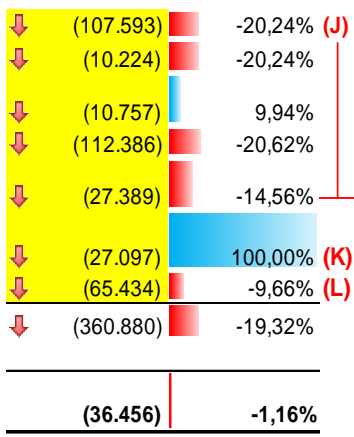

ร) (234.195) $-100,00 \%$ (E) 
(A) De acuerdo al análisis del estado de flujo de efectivo, la reducción de efectivo y equivalentes de efectivo en los años 2017 y 2016 se debe principalmente a las actividades de inversión por compras de maquinarias y equipos que ocurrieron en ambos años por los importes de S/34,444,000 y S/97,748,000 y a las actividades de financiamiento por la distribución de dividendos de ambos años por los importes de S/124,993,000 y S/154,401,000, respectivamente..

(B) Esta variación se explica por el aumento del ratio promedio de días de cuentas por cobrar en el año 2017. Ante los efectos causados por el efecto del fenómeno del niño, la Compañía tomó en consideración estas dificultades ambientales y otorgó a sus clientes, días adicionales de tolerancia para el pago de sus facturas.

(C) La variación de esta partida se debe a que en el año 2016 se realizó un cálculo para los pagos a cuenta según la utilidad tributaria generada en el año 2015, sin embargo en el año 2017 al realizar la declaración jurada del año 2016 se calcularon los pagos a cuenta a realizar sobre la base de la utilidad neta tributaria del año 2016 (que fue aproximadamente la mitad del año 2015), por lo que se redujo esta partida en aproximadamente $60 \%$.

(D) Esta variación se debe principalmente a la adquisición de repuestos y suministros diversos por el importe de S/34,191,000 relacionados a la puesta en funcionamiento de la nueva Planta de Piura.

(E) De acuerdo al Informe de los Estados Financieros al 31 de diciembre de 2017 y 2016 de la Compañía Cementos Pacasmayo S.A.A:

En septiembre de 2016, la Junta General de Accionistas de la Compañía aprobó el proyecto de escisión para efectuar la transferencia de un bloque patrimonial (compuesto por los activos y pasivos relacionados a la participación de la Compañía en Fosfatos del Pacífico S.A.) en favor de 
Fossal S.A.A. (empresa creada como subsidiaria de Inversiones ASPI S.A.). La finalidad de la escisión fue ordenar los activos y pasivos de la Compañía de acuerdo a la especialización de cada negocio, crear mayor flexibilidad para los accionistas y mayor claridad en las operaciones en el largo plazo.

Por cada acción común y de inversión de Cementos Pacasmayo S.A.A., los accionistas recibieron aproximadamente 0.20 acciones comunes y de inversión de Fossal S.A.A. y aproximadamente 0.80 acciones comunes y de inversión de Cementos Pacasmayo S.A.A.

En consecuencia, la inversión mantenida en Fosfatos del Pacífico S.A. al 31 de diciembre de 2016 ascendente a aproximadamente S/234,195,000 fue clasificada como una inversión en operaciones discontinuas y la participación en la pérdida neta de la misma, ascendente a $S / 851,000$ y $S / 6,307,000$ por los años 2017 y 2016; respectivamente, fue clasificada como participación en una inversión discontinua.

(F) Esta variación se debe a que la fecha de ejecución de la escisión, parte de las acciones de inversión cedidas a Fossal S.A.A., eran de propiedad de Cementos Pacasmayo S.A.A. (acciones en tesorería); como consecuencia, la Compañía recibió 9,148,373 acciones de inversión de Fossal S.A.A., dicha transacción se registró mediante un débito a inversiones disponibles para la venta, al costo, por un importe de $S / 21,206,000$.

(G) Esta variación se debe a que la Compañía evalúa sus Cross Currrency SWAPS en función al valor de mercado, utilizando métodos de cálculos de valor presente, tomando en cuenta la evolución del tipo de cambio año tras año.

(H) Esta variación en el año 2016, se debe a que la probabilidad de transferencia del bloque patrimonial de las acciones de la subsidiaria Fosfatos del Pacifico S.A. pertenecientes a la Compañía es alta y se tenía planeada realizar la 
escisión en marzo del año 2017, debido a esto es que la participación es Fosfatos se presenta a dicha fecha (31 de Diciembre de 2016) como inversión en operaciones discontinuas por el importe de S/234,195,000.

La variación del año 2017 se debe principalmente a que la Compañía ha decidido darle prioridad a sus inversiones en el desarrollo de productos relacionados con la fabricación, venta de cemento y soluciones constructivas. Como consecuencia de esta decisión, en el último trimestre del año Cementos Pacasmayo decidió no continuar con el proyecto Salmueras por lo que al 31 de diciembre de 2017 se ha registrado una provisión por deterioro en los activos de la Subsidiaria Salmueras Sudamericanas S.A.

(I) El aumento en las cuentas por pagar comerciales y diversas en el año 2017 en relación con el año 2016 se debe principalmente a que en el año 2017 la Compañía mantiene dividendos por pagar por le importe de $\mathrm{S} / 29,725,000$ a comparación de los S/5,070,000 que mantenía en el año 2016.

(J) Todas estas variaciones se deben a la escisión del bloque patrimonial de Fosfatos del Pacifico S.A. a FOSSAL S.A. mencionado anteriormente, el cual fue realizado en marzo del año 2017.

(K) La variación de esta partida se debe al registro de la pérdida neta por el efecto de los instrumentos financieros de la cobertura de flujos de efectivo (currency SWAPS). La cobertura de flujo de efectivo de los pagos futuros esperados fue evaluada como altamente efectiva (la Compañía se ha cubierto por la totalidad de los bonos corporativos) y en el estado separado de otros resultados integrales se incluye una pérdida no realizada de $\mathrm{S} / 38,230,000$ al 31 de diciembre de 2017 (pérdida no realizada de S/39,511,000 en el año 2016). 
(L) La reducción de esta partida en los años 2017 y 2016 se debe principalmente a la distribución y pago de dividendos por los importes de S/149,839,000 y S/155,236,000 además de los resultados de los ejercicios de ambos años.

\subsection{Estado de Resultados:}

A continuación se presenta el Estado de Resultados Separado de la Compañía Cementos Pacasmayo S.A.A. y sus correspondientes análisis vertical y horizontal, para detallar la composición y variaciones principales cifras de la Compañía desde el 31 de diciembre de 2015 al 2017:

Ventas

Costo de ventas Utilidad bruta

Ingresos (gastos) operativos

Gastos administrativos

Gastos de comercialización y distribución

Otros gastos operativos, neto

Total de ingresos (gastos), neto Utilidad operativa

Otros ingresos (gastos)

Ingresos financieros

Gastos financieros

Deterioro de inversion en subsidiarias

Participacion en resultado de subsidiarias

(Ganancia)Pérdida neta por diferencia en

cambio

Total de otros gastos, neto

Utilidad antes de impuesto a la renta

Impuesto a la renta

Utilidad neta de operaciones continuas

Perdida neta de operaciones discontinuas

Utilidad neta

\begin{tabular}{|c|c|}
\hline $\begin{array}{c}\text { Al } 31 \text { de diciembre } \\
\text { de 2015 }\end{array}$ & $\begin{array}{c}\text { Analisis } \\
\text { Vertical }\end{array}$ \\
\hline $\mathrm{S} /(000)$ & $\%$ \\
\hline
\end{tabular}

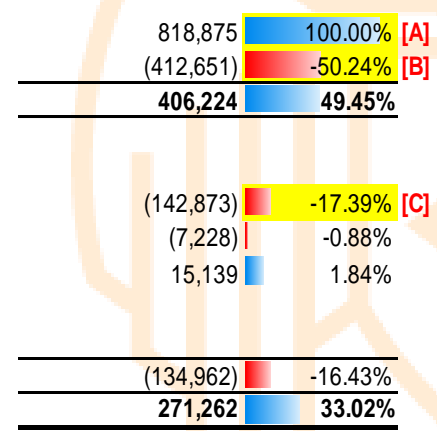

\begin{tabular}{l}
$33.02 \%$ \\
\hline
\end{tabular}

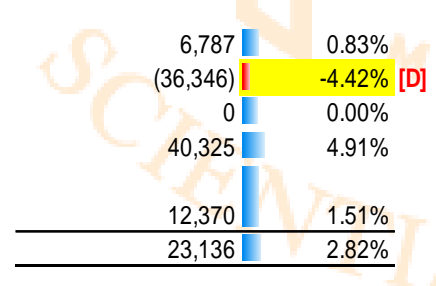

\begin{tabular}{l}
$294,398+35.84 \%$ \\
\hline$\quad 3$
\end{tabular}

$(71,062)$
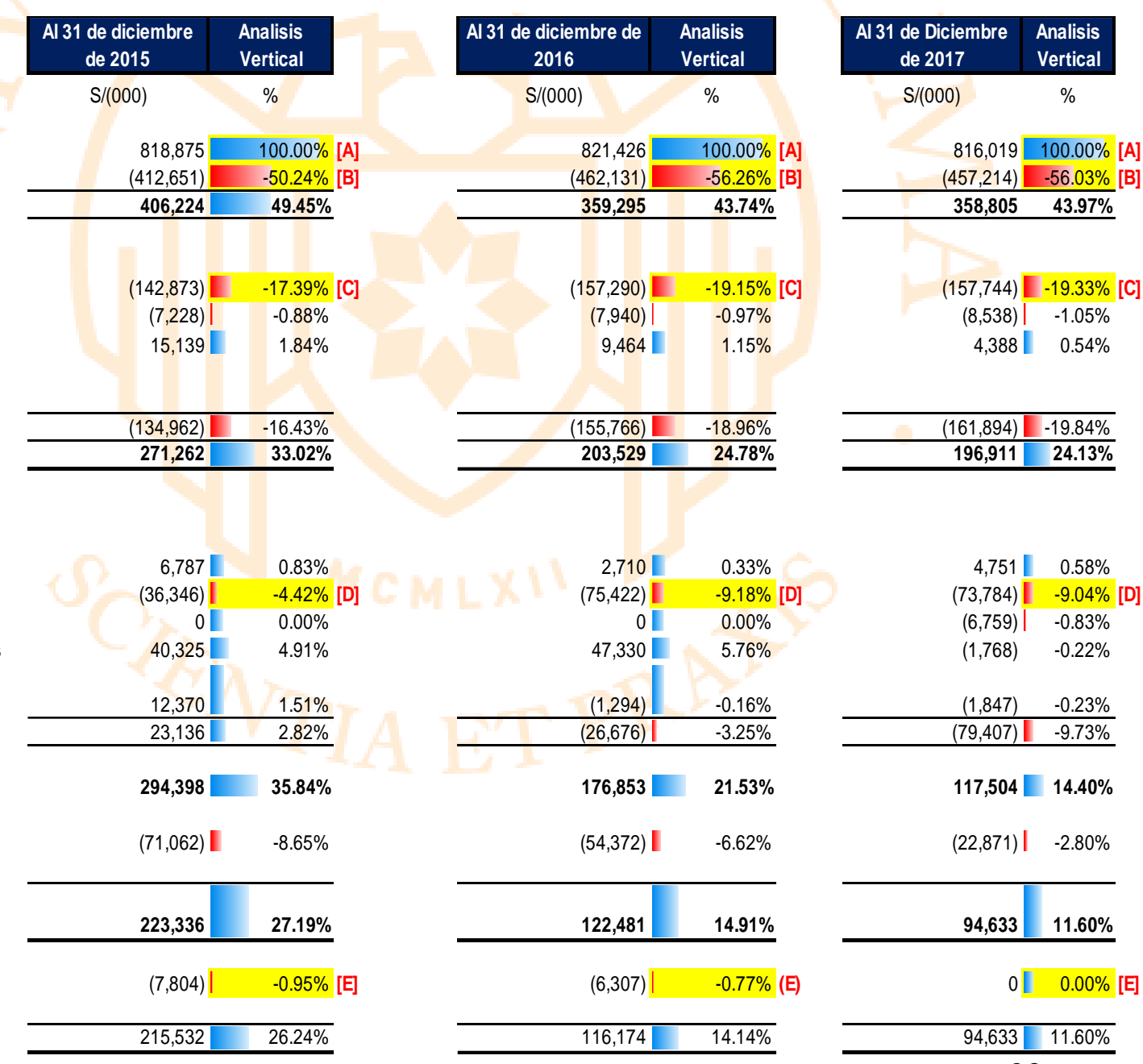

\begin{tabular}{ll}
196,911 & $24.13 \%$ \\
\hline
\end{tabular}
4,751 【 $0.58 \%$ $(73,784)$ I $-9.04 \%$ [D]

$(6,759) \mid-0.83 \%$

$(1,768) \quad-0.22 \%$

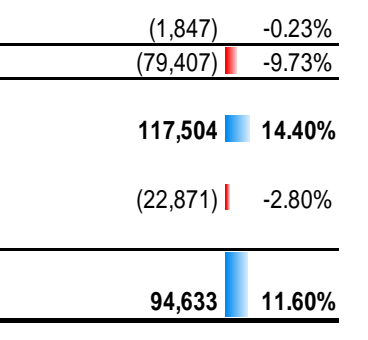

$010.00 \%$ [E]

$94,633 \quad 11.60 \%$ 


\subsubsection{Análisis Vertical de Estado de Resultados (expresado en miles de soles):}

(A) Las ventas a través de los años 2015 al 2017 está compuestas de la siguiente manera (en miles de soles), de acuerdo a la tabla 4.2:

Tabla 4.2

Composición de las ventas

\begin{tabular}{|l|c|c|c|c|}
\hline & 2015 & 2016 & 2017 & $\%$ al \\
\hline Cemento & 754,735 & 746,336 & 735,312 & $90 \%$ \\
\hline Cal & 64,140 & 75,090 & 80,707 & $10 \%$ \\
\hline Total & $\mathbf{8 1 8 , 8 7 5}$ & $\mathbf{8 2 1 , 4 2 6}$ & $\mathbf{8 1 6 , 0 1 9}$ & $\mathbf{1 0 0 \%}$ \\
\hline
\end{tabular}

Fuente: Estados Financieros Separados de Cementos Pacasmayo del 2017 al 2015.

(B) Esta Partida se compone principalmente de los suministros diversos consumidos, el mantenimiento y servicios prestados por terceros, la depreciación y amortización y los gastos de personal, para realizar la producción de cemento y cal.

(C) Los gastos de administración están compuestos principalmente por los gastos de personal (remuneraciones y derechos laborales) y los gastos por servicios prestados por terceros y otros.

(D) Los gastos financieros se componen principalmente por los gastos de intereses de los bonos corporativos y los gastos por el costo financiero de los instrumentos financieros de cobertura de flujos de efectivo (SWAPS).

(E) Este concepto es debido al proyecto de Escisión de Fosfatos del Pacifico S.A. mencionado anteriormente, cuya finalidad fue ordenar los activos y pasivos de la Compañía de acuerdo a la especialización de cada negocio. 
4.2.2 Análisis Horizontal del Estado de Resultados (expresado en miles de soles):

Al 31 de diciembre

de 2015

$S /(000)$

Ventas

Costo de ventas

Utilidad bruta

Ingresos (gastos) operativos

Gastos administrativos

Gastos de comercialización y distribución

Otros gastos operativos, neto

Total de ingresos (gastos), neto

Utilidad operativa

\section{Otros ingresos (gastos)}

Ingresos financieros

Gastos financieros

Deterioro de inversion en subsidiarias

Participacion en resultado de subsidiarias

(Ganancia)Pérdida neta por diferencia en

cambio

Total de otros gastos, neto

Utilidad antes de impuesto a la renta

Impuesto a la renta

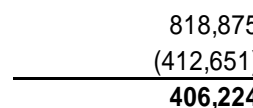

406,224

$(142,873)$

$(7,228)$

15,139

(34,962)

271,262

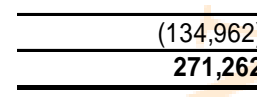

(1)

6,787

$6,346)$

40,325

12,370

23,136

294,398

$(71,062)$

223,336

Utilidad neta de operaciones continuas

Perdida neta de operaciones discontinuas

$(7,804)$

Utilidad neta
Al 31 de diciembre de

$$
2016
$$

$\mathrm{S} /(000)$

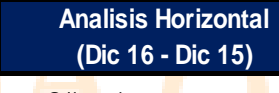

$\mathrm{S} /(000)$

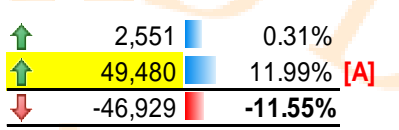

(462,131)

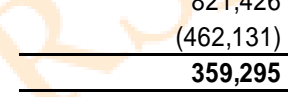

\begin{tabular}{ccc}
\hline & 49,480 & $11.99 \%$ \\
\hline 1 & $-46,929$ & $-11.55 \%$ \\
\hline
\end{tabular}

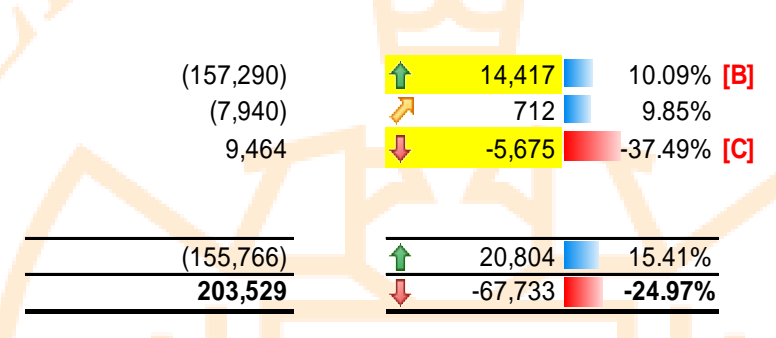

203,529

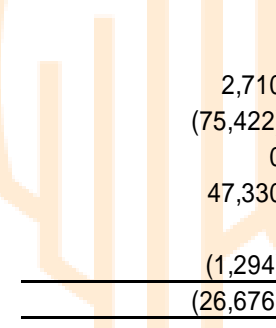

5. $-4,077-60.07 \%$

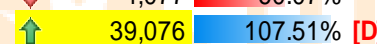

\begin{tabular}{|l|l|l|} 
ir & 39,076 & $107.51 \%$ \\
\hline & -1 & $0.00 \%$
\end{tabular}

个 $\quad 7,005-17.37 \%$
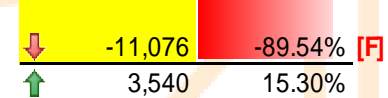

s. $-117,545--39.93 \%$

176,853

$(54,372)$

$\begin{array}{r}\hline \mathbf{2 2 3 , 3 3 6} \\ \hline(7,804) \\ \hline 215,532 \\ \hline\end{array}$

$\sqrt{-16,690}-23.49 \%$

122,481

\begin{tabular}{lll} 
8 & $-100,855$ & $-45.16 \%$ \\
\hline
\end{tabular}

$(6,307)$

$4-1,497-19.18 \%$

116,174
Al 31 de Diciembre

de 2017

$\mathrm{S} /(000)$
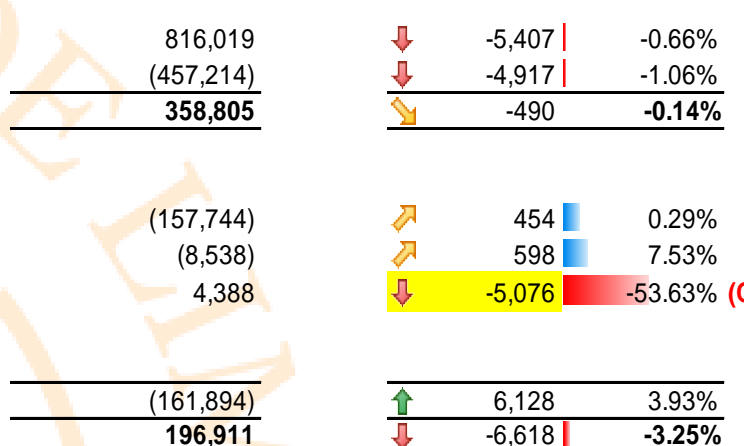

$\frac{(1,847)}{(79,407)}$

$(79,407)$

117,504

$(22,871)$ $\begin{array}{lll}\text { 入 } & 454 & 0.29 \% \\ \text { त } & 598 & 7.53 \%\end{array}$

ת. $-5,076-53.63 \%$ (C)

\begin{tabular}{lcc}
\hline & 6,128 & $3.93 \%$ \\
\hline$\sqrt{1}$ & $-6,618$ & $-3.25 \%$ \\
\hline
\end{tabular}

\begin{tabular}{rrr|r}
4,751 & 2 & 2,041 & $75.31 \%$ \\
$(73,784)$ & > & $-1,638$ & $-2.17 \%$
\end{tabular}

$(1,768)$

Analisis Horizontal

(Dic 17 - Dic 16)

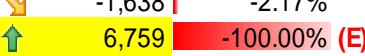

$\begin{array}{llll}\text { ป } & -45,562 & -96.26 \% & \text { (E) }\end{array}$

\begin{tabular}{rrrr} 
간. & 553 & $42.74 \%$ \\
\hline & 52.731 & $197.67 \%$ \\
\hline
\end{tabular}

ת $-59,349 \square-33.56 \%$

』 $-31,501--57.94 \%$

\& $\quad-27,848 \quad-22.74 \%$

94,633

94,633
ת $-6,307--100.00 \%$ (G)

\begin{tabular}{lll}
\hline$\sqrt{3}$ & $-21,541$ & $-18.54 \%$ \\
\hline
\end{tabular} 
(A) El aumento de los costos de venta en el año 2016 y 2017 se debe principalmente a la depreciación generada por la puesta en funcionamiento de la nueva planta de Piura en el mes de febrero del año 2016 (aumento en la depreciación).

(B) El aumento de los gastos administrativos en el año 2016 se debe a la puesta en funcionamiento de la planta de Piura, lo cual generó un mayor gasto por el nuevo personal (remuneraciones) contratado en la nueva planta. Además, que se realizaron un aumento de servicios de consultoría de Tecnología de Información (TI), medio ambiente, seguridad y servicios logísticos para la planta de Piura.

(C) La variación del año 2016 se debe principalmente a que se registró un cambio de la estimación de la provisión del cierre de mina por el importe de S/5,259,000. Esta provisión se creó sobre la base de estudios realizados por especialistas internos, los cuales dependen de los precios de mercados futuros para realizar el desmantelamiento.

Además, en el año 2015 se presentó una desvalorización de existencias por un stock de zinc que mantenía la Compañía, generado por la ex subsidiaria Corianta en el año 2011, sin embargo esa operación fue discontinuada y los activos relacionados provisionados, no obstante el stock de mineral seco de zinc se mantuvo con la intención de utilizarlo en las operaciones futuras o venderlo, en el año 2015 la Compañía decidió que las operaciones no eran probables en el futuro cercano, por lo que decidió provisionar el total del stock por el importe de $\mathrm{S} / 9,335,000$.

(D) Esta variación se debe a que una porción de los gastos financieros por los intereses de los bonos corporativos eran capitalizados en la nueva planta de Piura. Debido a su culminación y puesta en funcionamiento en febrero del año 2016, estos gastos dejaron de ser capitalizados a partir de esta fecha.

(E) El concepto de Deterioro de inversión en subsidiarias y la reducción de la participación en subsidiarias es debido al deterioro del proyecto Salmueras, mencionado anteriormente. Cementos Pacasmayo se quiere enfocar en sus 
inversiones con el desarrollo de productos relacionados con la fabricación, venta de cemento y soluciones constructivas.

(F) Esta variación se debe principalmente a que en el año 2015 los tipos de cambio de compra y venta variaron en $\mathrm{S} / 0.419$ y S/0.421 respectivamente en el año, mientras que en el año 2016 los tipos de cambio se mantuvieron más estables y solo variaron en $\mathrm{S} / 0.074$ y 0.07 , respectivamente.

(G) Este concepto es debido al proyecto de Escisión de Fosfatos del Pacifico S.A. mencionado anteriormente, cuya finalidad fue ordenar los activos y pasivos de la Compañía de acuerdo a la especialización de cada negocio.

\subsection{Análisis de ratios financieros:}

A continuación se analizarán los ratios que han presentado mayores variaciones del 2015 al 2017 (Para ver el detalle de todos los ratios calculados ver el anexo 5):

- Ratios de liquidez:

Tabla 4.3

Detalle de Ratios de liquidez del 2015 al 2017

\begin{tabular}{|l|c|c|c|}
\hline \multicolumn{1}{|c|}{} & & \multicolumn{2}{c}{} \\
\hline Capital de trabajo & $\mathbf{2 0 1 5}$ & $\mathbf{2 0 1 6}$ & $\mathbf{2 0 1 7}$ \\
\hline Ratio de liquidez & 390,710 & 337,368 & 333,651 \\
\hline Ratio de prueba acida & 3.72 & 3.46 & 3.14 \\
\hline Ratio de Prueba defensiva & 1.96 & 1.28 & 1.06 \\
\hline
\end{tabular}

Elaboración: Propia

Según Gitman (2003), los ratios de liquidez de una empresa miden la capacidad de la misma para enfrentar sus obligaciones de pago en el corto plazo (p. 49). 
En cuanto a los ratios de liquidez de la Compañía lo más resaltante es la variación del capital de trabajo, la prueba acida y prueba defensiva. Se puede apreciar que hubo una caída en el año 2016 en comparación con el año 2015, debido principalmente a una disminución en el efectivo, originado por el pago de dividendos en una proporción mayor en relación a la utilidad generada del año 2016 (comparándola con el año 2015). Esto significa que a la Compañía se le haría más difícil cancelar las deudas en el corto plazo.

- Ratios de solvencia:

Tabla 4.4

Detalle de Ratios de Solvencia del 2015 al 2017

\begin{tabular}{|l|c|c|c|}
\hline & $\mathbf{2 0 1 5}$ & $\mathbf{2 0 1 6}$ & $\mathbf{2 0 1 7}$ \\
\hline Ratio de deuda & $39.95 \%$ & $40.69 \%$ & $45.24 \%$ \\
\hline $\begin{array}{l}\text { Ratio de endeudamiento total } \\
\text { Ratio de endeudamiento CP }\end{array}$ & $66.54 \%$ & $68.59 \%$ & $82.61 \%$ \\
\hline $\begin{array}{l}\text { Ratio de endeudamiento LP } \\
\text { Ratio de cobertura de Gastos }\end{array}$ & $59.15 \%$ & $61.26 \%$ & $72.26 \%$ \\
\hline \begin{tabular}{l} 
Financieros \\
\hline
\end{tabular} & 9.10 & 3.34 & 2.59 \\
\hline
\end{tabular}

Elaboración: Propia

Según Gitman (J.Gitman, 2003), los ratios de solvencia indican en general la cantidad de dinero de terceros que se ha estado utilizando para financiar los activos que generan las ganancias de la Compañía. Normalmente, las deudas más representativas son las de largo plazo, debido a que estas suponen un compromiso de la Compañía durante un periodo largo de tiempo (p. 53)

En cuanto a los ratios de solvencia de la Compañía lo más resaltante es el aumento del ratio de endeudamiento total que ha aumentado a $82.61 \%$ en el año 2017 (72.26\% pertenece al ratio de endeudamiento de largo plazo y $10.35 \%$ a corto plazo), debido principalmente a la ejecución de la escisión del bloque patrimonial de Fosfatos del Pacifico S.A., por lo que el patrimonio fue reducido. Lo que significa que la proporción de la deuda sobre los 
recursos propios es muy alta y que la Compañía al año 2017 es muy dependiente de los préstamos de las entidades financieras. Además, el ratio de cobertura de gastos financieros se ha reducido en el año 2016, debido principalmente, a que la Compañía a partir del año 2016 dejo de capitalizar los intereses generados por los bonos corporativos, debido a que la planta de Piura empezó su total funcionamiento (se ha realizado el análisis sin considerar la capitalización de intereses y la variación no resulta significativa). Esto significa que la Compañía redujo su capacidad para cubrir sus gastos financieros (capacidad de endeudamiento).

- Análisis DUPONT

Tabla 4.5

Detalle de análisis DUPONT del 2015 al 2017

\begin{tabular}{|l|c|c|c|}
\hline DUPONT = Marg N x Rot Act x MAF & 2015 & 2016 & 2017 \\
\hline $\begin{array}{l}\text { Margen Neto } \\
\text { Ratio de rotación de Activos }\end{array}$ & $26.32 \%$ & $14.14 \%$ & $11.60 \%$ \\
\hline \begin{tabular}{l} 
Rentabilidad sobre Activos (ROA) \\
\hline
\end{tabular} & $6.66 \%$ & $3.69 \%$ & $3.44 \%$ \\
\hline Multiplicador de apalancamiento financiero & 1.67 & 1.69 & 1.83 \\
\hline Rentabilidad de Capital Propio (ROE) & $11.09 \%$ & $6.22 \%$ & $6.28 \%$ \\
\hline
\end{tabular}

Fuente: Elaboración propia

Según Gitman (2003), la fórmula DUPONT se utiliza para analizar minuciosamente los estados financieros de la empresa y evaluar su situación financiera. Además, permite a la empresa dividir su rendimiento en componentes de ganancias en ventas (Margen Neto) y de eficiencia de uso de activos (Rotación de activos). Finalmente, permite convertir el ROA 
calculado a ROE mediante la multiplicación con el multiplicador de apalancamiento financiero (MAF) (p. 65))

En el caso de la Compañía se puede apreciar que los ratios de Rentabilidad sobre Patrimonio (ROE) y Rentabilidad sobre Activos (ROA), han sufrido una disminución en el año 2016 en relación con el año 2015, debido incremento del costo de venta, principalmente por el aumento de la depreciación de los activos fijos relacionados con la nueva planta de Piura, además de un aumento de los gastos administrativos (mayor personal por planta Piura y contratación de servicios adicionales) y la no capitalización de intereses de la planta Piura en el año 2016. Además, en el caso de la rotación de activos este ha aumentado; pero debido principalmente a una disminución del activo por la escisión y no a las ventas, las cuales se han mantenido estables.

Ratios de actividad o gestión (expresado en días)

Tabla 4.6

Detalle ratio del ciclo del negocio

\begin{tabular}{|l|c|c|c|}
\hline & 2015 & 2016 & 2017 \\
\hline Rotación de Cuentas x Cobrar & 52 & 36 & 47 \\
\hline Rotación de Inventario & 223 & 236 & 259 \\
\hline Ratio de conversión de efectivo & 275 & 272 & 306 \\
\hline Rotación de Cuentas por Pagar & 108 & 91 & 111 \\
\hline Ratio del ciclo del negocio & 167 & 182 & 195 \\
\hline
\end{tabular}

Fuente: Elaboración propia

Según Court (2012), los ratios del ciclo del negocio mide que tan bien una Compañía gestiona sus activos. Estos son indicadores del desempeño operativo en curso, es decir que tan efectivamente los activos son usados por la compañía (p. 353). 
Según Gitman (J.Gitman, 2003), el ciclo de conversión de efectivo se refiere a la velocidad en la cual la Compañía es capaz de convertir las diversas cuentas en ventas o efectivo, es decir ingresos o egresos (p. 50).

En el caso de la Compañía se puede apreciar que lo más relevante es el aumento del ratio de conversión de efectivo del 2016 al 2017, esto debido al aumento del promedio de días de cuentas por cobrar, que se encuentra afectado por los efectos causados producto del fenómeno del niño, ya que la Compañía decidió tener una mayor consideración con sus diversos clientes en el cobro de sus facturas por las dificultades ambientales causadas. Además se puede apreciar que el ratio del ciclo del negocio está en aumento desde el año 2015 al 2017, lo cual significa que la Compañía tiene un mayor desfase entre el tiempo que se demora en convertir en efectivo sus ventas y el pago de sus obligaciones.

Ratios de rentabilidad

\begin{tabular}{|l|c|c|c|}
\hline Margen Bruto & 2015 & 2016 & 2017 \\
\hline EBITDA & $49.61 \%$ & $43.74 \%$ & $43.97 \%$ \\
\hline EBITDA / Ventas & 315,370 & 284,076 & 292,515 \\
\hline
\end{tabular}

Fuente: Elaboración Propia

Según Monteverde (2012), para calcular el EBITDA se debe utiliza el Estado de Ganancias y Pérdidas, y tomar lo que se conoce como la utilidad antes de intereses, impuestos y la depreciación, es por esto que se puede considerar como un indicador rápido de rentabilidad del negocio. Sin embargo, solo representa los flujos operativos, es decir no significa que sea un flujo de efectivo.

En el caso de la Compañía, el EBITDA ha sufrido una reducción en el año 2016 en comparación con el año 2015, debido principalmente al aumento de 
los gastos administrativos, producto del inicio de la producción en la planta Piura.

\section{CAPÍTULO 5: VALORIZACIÓN DE LAACCIÓN DE LA COMPAÑÍA CEMENTOS PACASMAYO S.A.A.}

Según Fernández (2001), para determinar el valor intrínseco de la acción de la Compañía Cementos Pacasmayo S.A.A. se utilizará el método un flujo de caja descontado, el cual pretende determinar el valor de la Compañía a través de la estimación de los flujos de efectivo que generará en un futuro, producto de sus operaciones, para luego descontarlos a una tasa de descuento apropiada según el riesgo de dichos flujos. Normalmente se recurre a este método para valorizar acciones, debido a que es el único conceptualmente correcto, porque el valor de las acciones de una Compañía proviene de la capacidad que tiene para generar flujos de efectivo futuros para los propietarios (p. 39).

De acuerdo a lo expuesto, para llegar a realizar la valorización de las acciones de la Compañía Cementos Pacasmayo S.A.A. a través de un flujo de caja descontado, se necesita una tasa de descuento que considere las variables correctas según las condiciones del mercado y un flujo de efectivo basado en supuestos concretos para realizar la proyección de los flujos de caja esperados. 


\subsection{Tasa de descuento}

Según Forsyth (2004), para calcular la tasa de descuento se utilizará el costo promedio ponderado de capital (WACC), el cual es un promedio ponderado entre un coste y una rentabilidad exigida (p.205).

Se encuentra determinado por las siguientes variables:

$\mathrm{WACC}=\mathrm{Ke}^{*} \mathrm{We}+\mathrm{Kd}^{*} \mathrm{Wd}(1-\mathrm{t})$

Siendo:

$\mathrm{Ke}=$ Costo del capital propio

$\mathrm{Kd}=$ Costo de la deuda

$\mathrm{We}=$ Peso del Capital Propio al valor de mercado.

$\mathrm{Wd}=$ Peso de la deuda al valor de mercado.

$\mathrm{T}=$ tasa de impuestos proyectada

\subsubsection{Costo de capital propio}

En el caso del costo del capital propio, se ha optado por utilizar la metodología determinada por Damodaran (2017), quien llega a extender el modelo del CAPM regular y lo adecua a la región Latinoamérica, para países emergentes. Este se encuentra determinado de la siguiente manera:

Costo de capital $=$ Tasa libre de riesgo + Beta $($ Riesgo de mercado - Tasa libre de riesgo $)$ + riesgo país x el factor de volatilidad

o Tasa libre de riesgo: Se utilizará el rendimiento del bono del tesoro americano a 10 años. Al cierre del año 2017, el rendimiento de los bonos del tesoro americano es de $2.41 \%$. 
o Beta: De acuerdo al profesor Damodaran (2017c) el beta desapalancado del sector construcción de los mercados emergentes en el año 2017 fue de 0,72 (basado en 529 empresas de suministros para la construcción), por lo que al apalancar dicho beta en base a Cementos Pacasmayo obtenemos un beta apalancado de 0,85 .

o Prima por riesgo de mercado: Para calcular este concepto se tomó en cuenta la información publicada por Damodaran entre el diferencial entre el rendimiento promedio anual del mercado (S\&P 500) y el rendimiento de los bonos de EEUU. Se tomó el promedio geométrico de los años 1928 al 2017 (4.77\%), calculado por Damodaran (2017b).

o Riesgo país por el factor de volatilidad: Para calcular esta variable se toma en cuenta el Emerging Markets Bond Índex (EMBI), que es el diferencial entre el rendimiento de los bonos del Perú contra el rendimiento de los bonos del tesoro americano. Al 31 de diciembre de 2017, el riesgo país ascendía a 1.39\%, publicado por el BCRP (2018), además el riesgo país debe ser ajustado por el ratio de volatilidad relativa, el cual se obtiene luego de dividir la desviación estándar del índice general de la bolsa (IGVL) sobre la desviación estándar del rendimiento de los bonos globales, dando un valor de 1.19 (SBS, 2017). Por ende, el cálculo del riesgo país por el factor de volatilidad se ha determinado con el valor de $1.65 \%$.

Tomando en cuenta todas estas variables el cálculo del costo del capital propio se calcula de acuerdo a la siguiente tabla:

Tabla 5.1

Cálculo del Costo de Capital

\begin{tabular}{|l|c|l|}
\hline & Tasa & \\
\hline Tasa libre de riesgo & $2.41 \%$ & Damodaran \\
\hline Beta & 0.85 & Damodaran \\
\hline
\end{tabular}




\begin{tabular}{|l|c|c|}
\hline Prima por riesgo & $4.77 \%$ & Damodaran \\
\hline Riesgo País & $1.65 \%$ & BCRP \\
\hline Costo de Capital & $8.11 \%$ & \\
\hline
\end{tabular}

Fuente: BCRP (2017) y Damodaran (2017).

\subsubsection{Costo de la deuda}

La principal fuente de financiamiento de la Compañía proviene de los bonos corporativos “bullet" emitidos el año 2013. De acuerdo a Bloomberg (2017) el costo de la deuda de acuerdo a la tasa de rendimiento de mercado (YTM) es de $3.68 \%$ al cierre del año 2017.

En cuanto a la tasa de impuestos, cierre del año 2017 fue de $29.5 \%$, sin embargo para el cálculo del escudo fiscal se utilizará una tasa de 33.5\%, producto del promedio de la tasa de impuesto a la renta efectiva de la Compañía durante los 5 últimos años.

\subsubsection{Calculo del WACC}

Tabla 5.2

Calculo del WACC

\begin{tabular}{|l|r|r|}
\hline & Tasa & \\
\hline Costo del capital propio & $8.11 \%$ & \\
\hline Costo de la deuda & $3.68 \%$ & YTM Bono corporativo - Bloomberg \\
\hline Deuda/(Deuda + Capital) & $21.7 \%$ & Valor de mercado - Bloomberg \\
\hline Capital/Deuda + Capital) & $78.3 \%$ & Valor de mercado - bloomberg \\
\hline Tasa de impuestos & $33.50 \%$ & \\
\hline WACC & $6.88 \%$ & \\
\hline
\end{tabular}

Fuente: Bloomberg (2017), Damodaran (2017), BCRP (2017), SBS (2017)

Elaboración: Propia

Finalmente, de acuerdo Coss $\mathrm{Bu}$ (2005) al transformar la tasa denominada en dólares a soles se utiliza la fórmula de paridad de tasas, tomando en cuenta la inflación peruana estimada (2\%) y la americana (2\%) BCRP (2018) como mejor aproximación de las 
expectativas del mercado, de acuerdo a lo estimado por el BCRP. Dando un total de WACC en soles de $6.88 \%$.

\subsection{Flujo de caja de efectivo a 10 años.}

De acuerdo a Forsyth (2004), se debe proyectar el flujo de caja que se espera que generen los activos asociados con el negocio, en base a supuestos. En cuanto al horizonte determinado, un plazo común para la proyección de flujos de caja futuros es 10 años (p. 202). 


\subsubsection{Principales Supuestos para proyectar el flujo de efectivo}

1) Periodo de proyección: 10 años en moneda nacional (soles) (desde el año 2018 al año 2027)

2) Ventas: Para realizar la proyección de las ventas de la Compañía se ha realizado en base a las proyecciones de crecimiento del PBI del sector de construcción realizadas por el MEF (2018). Se ha utilizado esta tasa debido al proyecto de "Reconstrucción Nacional", explicado en el anexo 1 y a los proyectos que se van a llevar a cabo según el Cuadro 4: "Grandes proyectos por iniciar al final del año 2017”, descrito en el capítulo 1.

3) Márgenes: Para los años del 2018 al 2027 se utilizará un promedio de los porcentajes que representan cada uno de los conceptos según el análisis vertical realizado por los años 2016 y 2017 (no se utilizará el año 2015 debido a que aún no se encontraba en funcionamiento la planta Piura por lo que no se considera como un año representativo). Finalmente para los gastos financieros se asumirá que se mantendrán estables, ya que la mayoría del gasto por este importe proviene de los intereses pagados por el bono corporativo emitido y el cual se renovará en el año 2023. Para mayor detalle ver trabajo realizado en el anexo 3.

4) Impuesto a la renta: Se utilizó una tasa promedio efectiva de los últimos 5 años dando un valor de impuesto a la renta por $33.5 \%$.

5) Dividendos: La empresa mantiene una política de dividendos estable, por lo que se han calculado en base al promedio histórico de los últimos 3 años definidos por la utilidad neta.

6) Tasa de perpetuidad: Se ha calculado como $2 \%$, producto del cálculo de la inflación a largo plazo estimada por el BCRP (2018). 
7) Financiamiento: Se considera el pago de la tasa cupón por $4.50 \%$, por los bonos corporativos a vencer en el año 2023, después de la cual se estima que la Compañía realizará una nueva emisión de deuda por el mismo monto y la misma tasa cupón para mantener la estructura de financiamiento.

8) NOF (Necesidades operativas de fondos): Según Oliete (2012), para el cálculo del NOF se toma en cuenta los siguientes conceptos: Cuentas por cobrar comerciales, Cuentas por cobrar con relacionadas, inventarios, Cuentas por pagar comerciales, Cuentas por pagar con relacionadas y otras cuentas por pagar a corto plazo, para mayor detalle ver trabajo realizado en el anexo 4 y 2 . Estos conceptos se tomarán de las proyecciones a 10 años del estado de situación financiera según el anexo 1.

9) CAPEX: De acuerdo a una entrevista realizada por Salaverry (2017) a Manuel Ferreyros, vicepresidente de Administración y Finanzas, el CAPEX estimado para los años 2018 y 2019 es de US\$ 21 millones y en adelante un aproximado de US\$15 millones. La diferencia corresponde a una mayor inversión en los primeros años en camiones y en la red de distribución de concreto. Para mayor detalle sobre la proyección del CAPEX y la capacidad de utilización ver anexo 2 .

10) Valor patrimonial de las acciones de inversión: Este efecto patrimonial corresponde a las acciones de inversión de la Compañía, las cuales han sido calculadas mediante un promedio de las cotizaciones de los últimos dos años. 


\subsection{Resultados obtenidos de la valorización}

\begin{tabular}{|c|c|c|c|c|c|c|c|c|c|c|c|}
\hline FCFF & 2018 & 2019 & 2020 & 2021 & 2022 & 2023 & 2024 & 2025 & 2026 & 2027 & $2027 \mathrm{~T}$ \\
\hline Ebit & 281,086 & 303,010 & 326,645 & 352,124 & 379,589 & 409,197 & 441,115 & 475,522 & 512,612 & 552,596 & 552,596 \\
\hline Impuesto & $-94,164$ & $-101,509$ & $-109,426$ & $-117,961$ & $-127,162$ & $-137,081$ & $-147,773$ & $-159,300$ & $-171,725$ & $-185,120$ & $-185,120$ \\
\hline Ebit $x(1-T)$ & 186,922 & 201,502 & 217,219 & 234,162 & 252,427 & 272,116 & 293,341 & 316,222 & 340,887 & 367,476 & 367,476 \\
\hline Depreciacion & 66,177 & 93,649 & 95,853 & 97,428 & 99,002 & 110,118 & 118,054 & 119,628 & 121,202 & 122,777 & 104,389 \\
\hline Capex & $-69,300$ & $-69,300$ & $-69,300$ & $-49,500$ & $-49,500$ & $-349,500$ & $-249,500$ & $-49,500$ & $-49,500$ & $-49,500$ & $-105,440$ \\
\hline Variacion de NOF & 7,532 & $-26,327$ & $-28,381$ & $-30,594$ & $-32,981$ & $-35,553$ & $-38,326$ & $-41,316$ & $-44,539$ & $-48,013$ & $-48,013$ \\
\hline Flujo de Caja libre & 191,332 & 199,524 & 215,392 & 251,495 & 268,948 & $-2,819$ & 123,568 & 345,034 & 368,051 & 392,741 & 318,413 \\
\hline
\end{tabular}

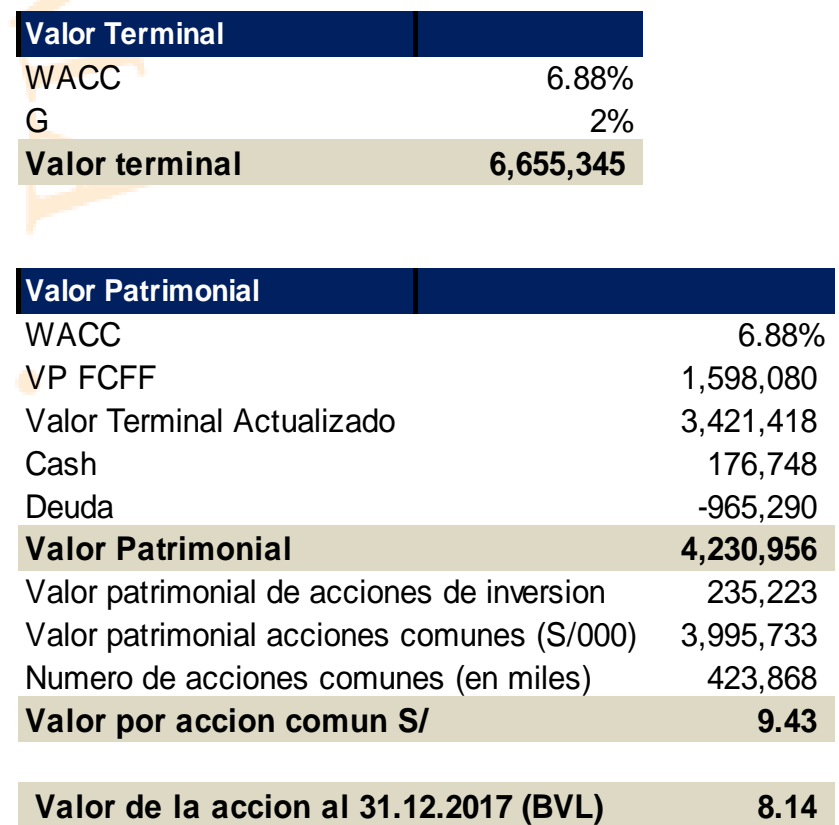

$\operatorname{xxxix}$ 


\section{CAPÍTULO 6: CONCLUSIONES Y RECOMENDACIONES}

\subsection{Conclusiones}

- La Compañía a través del método de flujos descontados al 31 de diciembre de 2017 tiene un valor patrimonial de las acciones comunes de S/4,230,956, dando un total de S/9.43 por acción común, un $15.81 \%$ por encima del valor de la acción común en la Bolsa de Valores de Lima (BVL).

Actualmente, la estructura de capital de Cementos Pacasmayo ha sido afectada por el deterioro de su subsidiaria Salmueras Sudamericanas y la escisión del proyecto Fosfatos (reducción del patrimonio neto), por lo que el ratio de endeudamiento ha aumentado considerablemente desde el año 2015 al 2017.

- Actualmente, la Compañía tiene suficiente expansión disponible de la capacidad de utilización de sus plantas de Piura y Pacasmayo para afrontar el crecimiento económico causado por los diversos proyectos en curso y por realizar en el norte del país ("Proyecto de Reconstrucción con cambios"), hasta aproximadamente el año 2023. 


\subsection{Recomendaciones}

- De acuerdo al valor calculado mediante el flujo de caja descontado (FCD) , tomando en consideración las diversas variables y supuestos expuestos anteriormente, la acción común de Cementos Pacasmayo se encuentra valorizada en S/9.43, lo cual significa que se encuentra valuada por encima del valor de la acción en la Bolsa de Valores de Lima (BVL) por 15.81\% (S/8.14). Por esto, se recomienda comprar a los accionistas interesados en invertir en el sector de construcción e infraestructura del país.

- Se recomienda además que la Compañía emita capital propio en los próximos años, debido a que producto de la escisión de Fosfatos del Pacifico S.A. y el deterioro del proyecto Salmueras su estructura de capital ha sido afectada, aumentando el porcentaje de deuda sobre los activos totales.

- De acuerdo al crecimiento del sector de construcción del país se recomienda que Cementos Pacasmayo invierta en el año 2023 en una nueva planta similar a la de Piura para poder atender al proyecto "Reconstrucción con cambios", entre otros y pueda incrementar sus ventas. 


\section{REFERENCIAS}

Damodaran A. (2017). Cost of Capital by Industry Sector. Obtenido de http://pages.stern.nyu.edu// adamodar/New_Home_Page/datacurrent.html\#discr ate

Damodaran A. (2017b). Annual Return on Stocks, T Bonds and T.Bills:1928-2017. Obtenido de http://pages.stern.nyu.edu/ adamodar/New_Home_Page/datafile/histretSP.html

Damodaran A (2017c). Betas by sector (US). Obtenido de http://pages.stern.nyu.edu/ adamodar/New_Home_Page/datafile/Betas.html

ASOCEM. (2016). Detalle de Produccion del Cemento. Obtenido de http://www.asocem.org.pe/productos-a/cual-es-el-proceso-de-fabricacion-delcemento

Asociados, A. \&. (2017). Informe Anual Cementos Pacasmayo S.A.A. y Subsidiarias.

Barletta, F., Pereira, M., Robert, V., \& Yoguel, G. (2013). Argentina: dinámica reciente del sector de software y servicios informáticos. Revista de la CEPAL(110), 137155. Obtenido de http://www.cepal.org/publicaciones/xml/1/50511/RVE110Yoqueletal.pdf

BCRP. (Junio de 2018). Banco Central de Reserva del Peru. Obtenido de http://www.bcrp.gob.pe/docs/Publicaciones/ReporteInflacion/2018/junio/reporte-de-inflacion-junio-2018.pdf

BCRP. (2018). Informe de Actualziacion de proyecciones Macroeconomicas 2018-2021. 
BCRP. (Junio de 2018). Panorama actual y proyecciones macroeconómicas 2018-2019. Obtenido de http://www.bcrp.gob.pe/docs/Publicaciones/ReporteInflacion/2018/junio/reporte-de-inflacion-junio-2018.pdf

Bu, R. C. (2005). Analisis y evaluacion de proyectos de inversion.

Bunges, M. (2004). La investigación cientifica. Tercera Edicion.

BVL. (2018). Bolsa de Valores de Lima. Obtenido de https://www.bvl.com.pe

Capital, L. (Setiembre de 2018). Liquid Capital. Obtenido de https://liquidcapitalcorp.com/es/blog-es/utilice-esta-formula-para-determinar-elciclo-de-conversion-de-efectivo-de-su-compania/

Choy, M., \& Chang, G. (2014). Medidas macroprudenciales aplicadas en el Perú. Lima: Banco Central de Reserva del Perú. Obtenido de http://www.bcrp.gob.pe/docs/Publicaciones/Documentos-deTrabajo/2014/documento-de-trabajo-07-2014.pdf

EY. (2017). "Cementos Pacasmayo S.A.A. y subsidiarias Estados financieros consolidados al 31 de diciembre de 2016 y de 2015, junto con el dictamen de los auditores independientes".

EY. (2017). "Cementos Pacasmayo S.A.A. y subsidiarias Estados financieros consolidados al 31 de diciembre de 2017 y de 2016, junto con el dictamen de los auditores independientes".

Fernandez, P. (2001). Valoracion de empresas.

Forsyth, J. A. (2004). Finanzas Empresariales, rentabilidad y valor.

García Nieto, J. P. (2013). Consturye tu Web comercial: de la idea al negocio. Madrid: RA-MA.

J.Gitman, L. (2003). Administración Financiera. 
LP., B. (2017). CPACASC1 PE - Datos Generales. Obtenido de http//:www.bloomberg.com

Monteverde, E. C. (2012). Finanzas Corporativas.

Oliete, B. (2012). Análisis y gestión de las Necesidades Operativas de Fondos. Obtenido de https://www.empresaactual.com/las-necesidades-operativas-de-fondos/

Pacasmayo. (2016). Nota de Prensa Cementos Pacasmayo por los resultados al 31.12.16.

Pacasmayo. (2018). Cementos Pacasmayo - Nota de Prensa. Obtenido de https://www.cementospacasmayo.com.pe/Aplicaciones/Web/webpacasmayo.nsf /Resultados_1T18.pdf

Pacasmayo, C. (2017). Estados financieros separados al 31 de diciembre de 2017 y de 2016, junto con el dictamen de los auditores independientes.

Pacasmayo, C. (2017). Estados financieros separados al 31 de diciembre de 2016 y de 2015, junto con el dictamen de los auditores independientes.

Pacasmayo, C. (2018). Cementos Pacasmayo - Inversionistas. Obtenido de https://www.cementospacasmayo.com.pe/Aplicaciones/Web/webpacasmayo.nsf /xsp_page.xsp?page=inversionistas\&tab $=15$

Pacasmayo, C. (2018). Nuestras canteras, Cementos Pacasmayo. Obtenido de https://www.cementospacasmayo.com.pe/Aplicaciones/Web/webpacasmayo.nsf /xsp_pcantera.xsp?tab=74

Salaverry, E. F. (2017). Valorizacion de Cementos Pacasmayo S.A.A. 2017.

SBS. (2017). Curva Cupon cero. Obtenido de http://www.sbs.com.pe

SMV. (2018). Superintendencia del Mercado de Valores. Obtenido de http://www.smv.gob.pe/ConsultasP8/temp/CPSAA\%20Individ.al\%20311217\%2 016.pdf 
Wittmann, R. (2006). ¿Hubo una revolución en la lectura a finales del siglo XVIII? En G. Cavallo, \& R. Chartier, Historia de la lectura en el mundo occidental (págs. 435-472). México D.F.: Santillana.

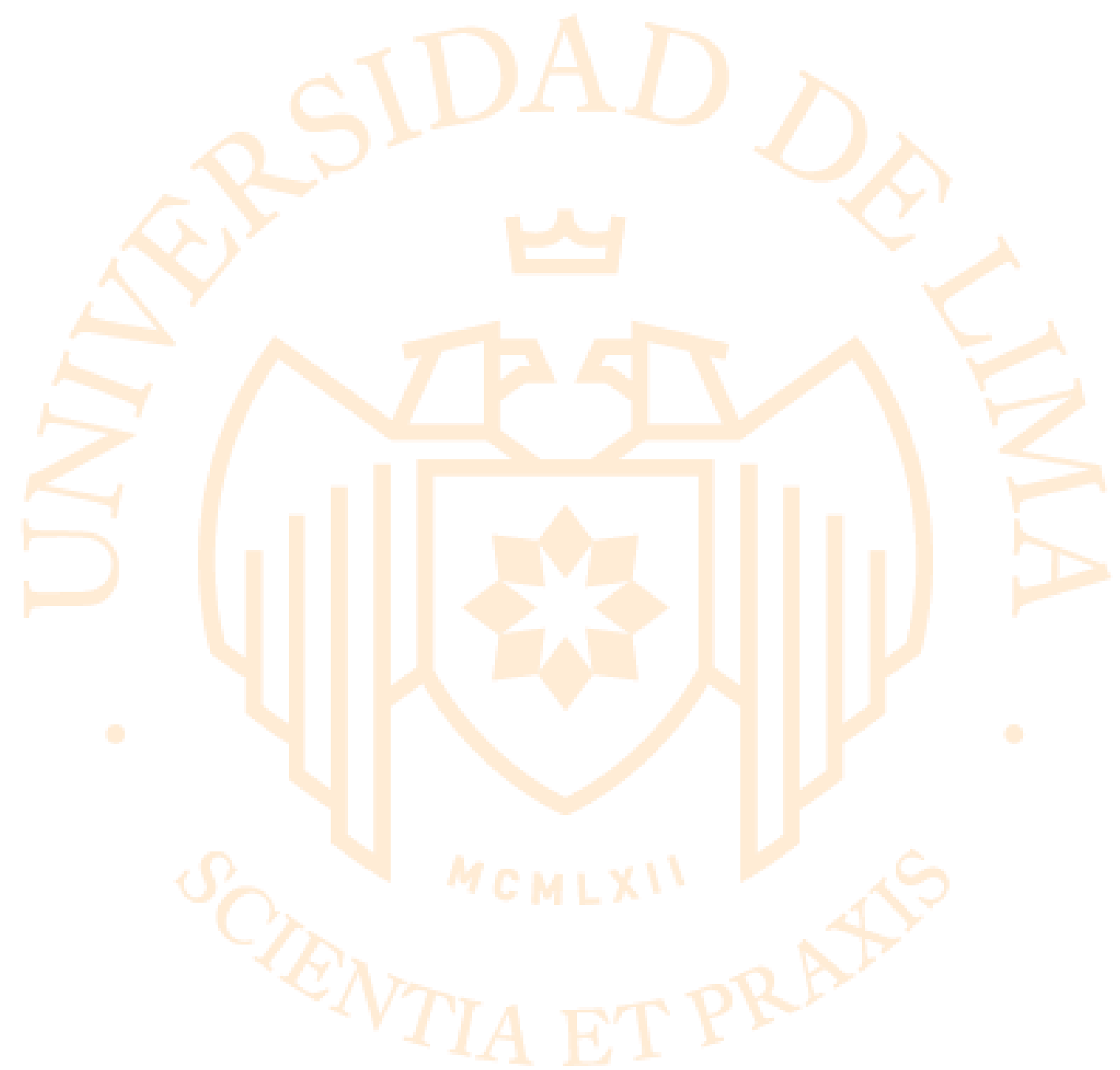




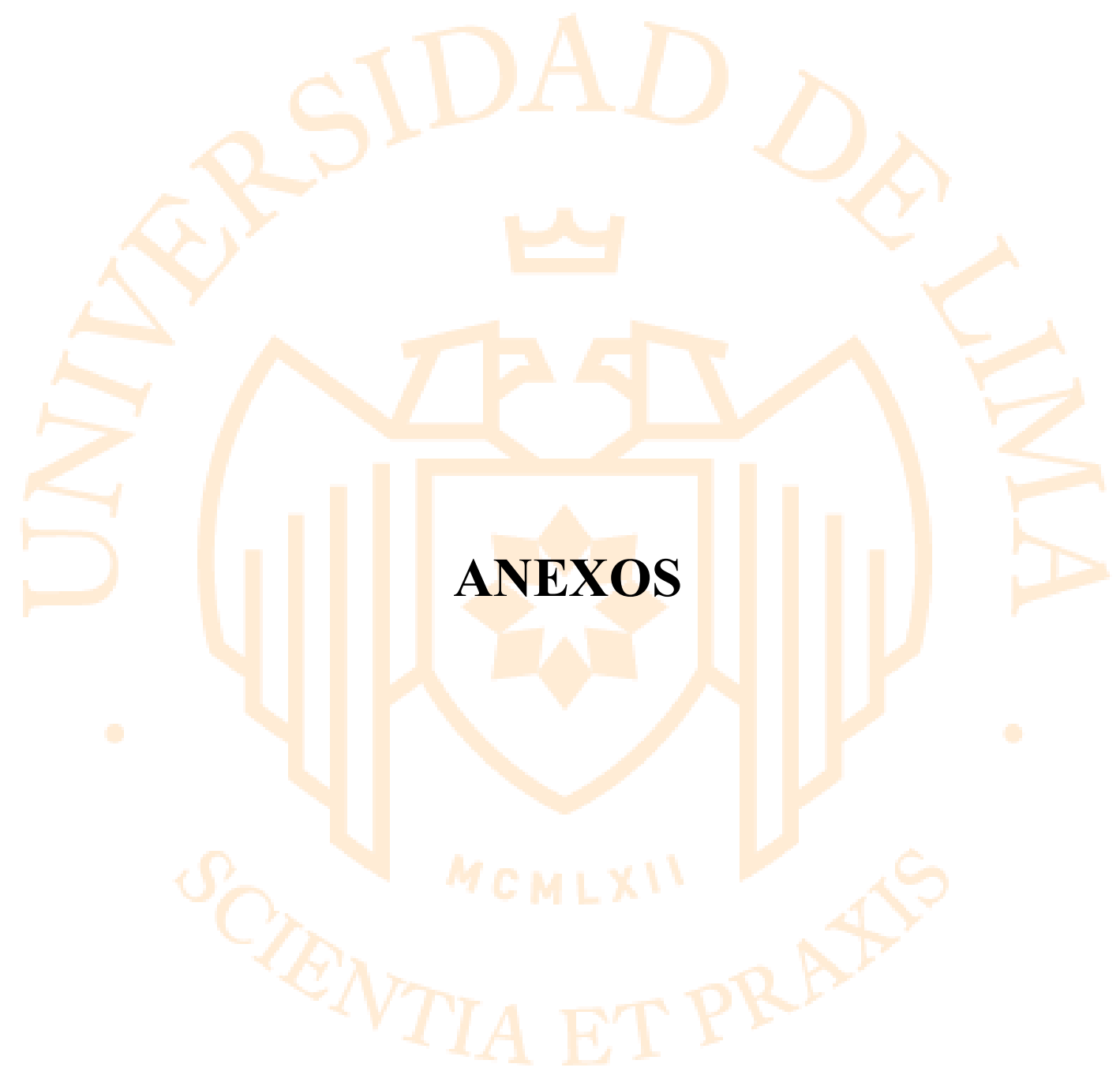




\section{Anexo 1: Proyecto de Reconstrucción con cambios}

En el norte del país se va a realizar una gran inversión en infraestructura de parte del estado (aproximadamente S/25 mil millones), por los trabajos de reconstrucción de los efectos causados por El Fenómeno del Niño, llamado "Plan de Reconstrucción con Cambios", este monto se piensa invertir a partir del año 2018 hasta el 2015.

\section{País S/ 25,655 MM}

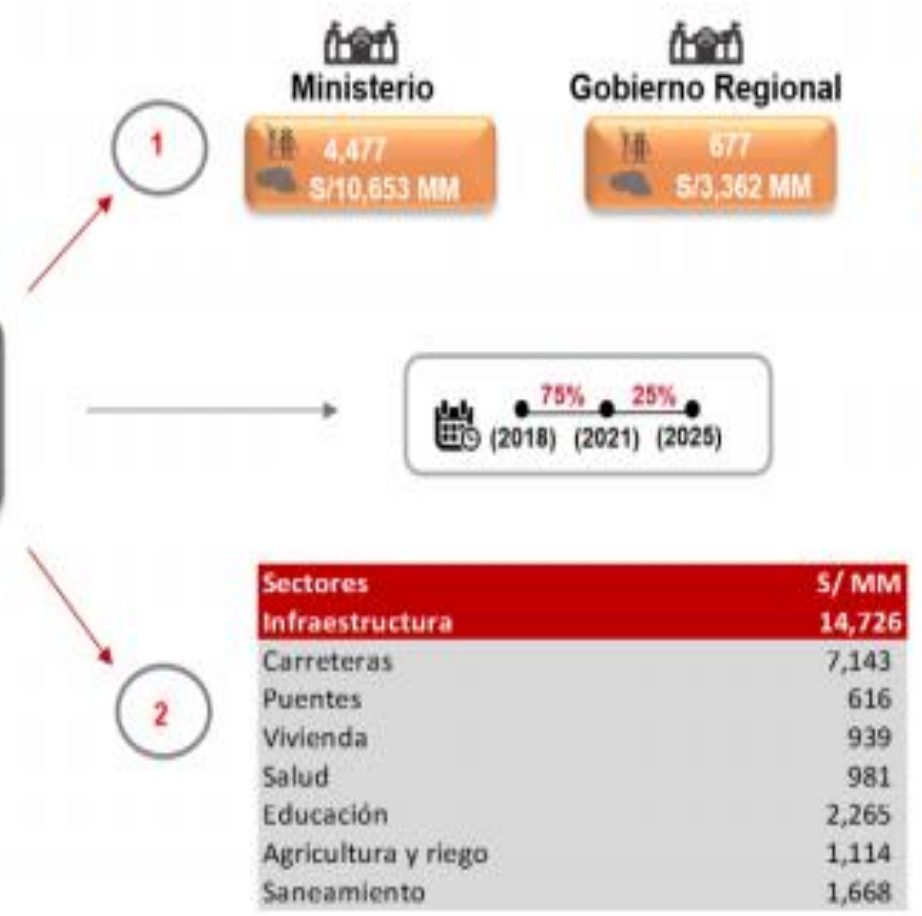

Fuente: Nota de prensa de Cementos Pacasmayo S.A.A al 31.12.17 


\section{Anexo 2: Proyección del Estado de Situación Financiera del 2018 al 2027}

Para realizar la proyección del Estado de Situación Financiera desde el año 2018 al año 2027, se calculó al multiplicar el activo total del último año reportado por el porcentaje de aumento de las proyecciones de ventas realizadas en el Estado de Resultados (PBI del sector construcción) y luego se le asignó a cada concepto un porcentaje del mismo en base al promedio del análisis vertical de los conceptos de los años 2015 al 2017. Cabe resaltar que en el caso de inversiones disponibles para la venta se ha decidido mantener estable, debido a que el movimiento generado en el año 2017 que provocó un aumento a S/21,206,000 se debió a la escisión del bloque patrimonial.

En el caso de la proyección de los conceptos de instrumentos financieros y otros resultados integrales acumulados, se han decidido mantener estables, esto se debe a que ambos conceptos varían según el valor razonable de cada año, por lo que sería inexacto y podría afectar la razonabilidad de los estados financieros proyectados si se asume que variarían según el promedio de variaciones verticales de años pasados. Adicionalmente, para el caso de capital social, acciones de inversión, acciones en tesorería y capital adicional, se asume que no se van a realizar a realizar emisiones o compras de acciones en tesorería en años futuros, por lo que todas estas partidas se mantendrán constantes.

Asimismo para la proyección de los dividendos declarados y pagados se ha realizado el cálculo del ratio la utilidad neta / dividendos pagados y declarados de los años 2015 al 2017 dando un promedio de S/1.228 por cada sol de utilidad, este promedio será multiplicado por la utilidad de los años posteriores para calcular el pago de dividendos correspondientes. 
Finalmente, en el caso de propiedad, planta y equipo, se ha decidido proyectar en base al promedio del análisis horizontal de los años 2015-2016 y 2017 -2016, debido a que se estima que el CAPEX y depreciación asociados serán similares en años posteriores, sin embargo también se ha considerado que estos aumentaran por el importe de S/300,000,000 y S/200,000,000, en los años 2023 y 2024, debido a que en el año 2024 se llegara aproximadamente a la misma capacidad de utilización que se mantenía en el año 2014, por lo que la compañía tendría que invertir en una planta similar a la de Piura en los años mencionados, para mayor información ver el siguiente análisis de capacidades: 
Crecimiento de demanda (\%)

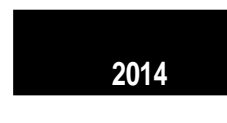

Real

Produccion Cemento

Produccion Clinker

2350,20

1241,50

$70,80 \%$

$67,60 \%$

2015

Cemento

2016

1201,90

2276,00

2017

2018

2019

$7,80 \%$

2020

$\begin{array}{ll} & \text { Proyectado } \\ 2021 & 2022\end{array}$

$7,80 \%$

2023

$\begin{array}{llll}92,90 & 2491,63 & 2685,98 & 2895,48\end{array}$

$7,80 \% \quad 7,80 \%$

$7,80 \%$

2024

$7,80 \%$

$\mathbf{2 0 2 5}$

$7,80 \%$

$64,50 \%$

$\begin{array}{ll}1730,6 & 1641,3 \\ 40,60 \% & 39,40 \%\end{array}$

$2241,15 \quad 2415,96-2604,40$

2807,55

3026,54

3262,61

3517,09

Clinker

$59,10 \%$

$45,80 \%$

$49,92 \%$

$-53,82 \%$

$58,01 \%$

$53,80 \% \quad 58,00 \%$

$62,52 \% \quad 67,40 \%$

$43,40 \%$

$46,78 \%$

$50,43 \%$
$56,18 \%$

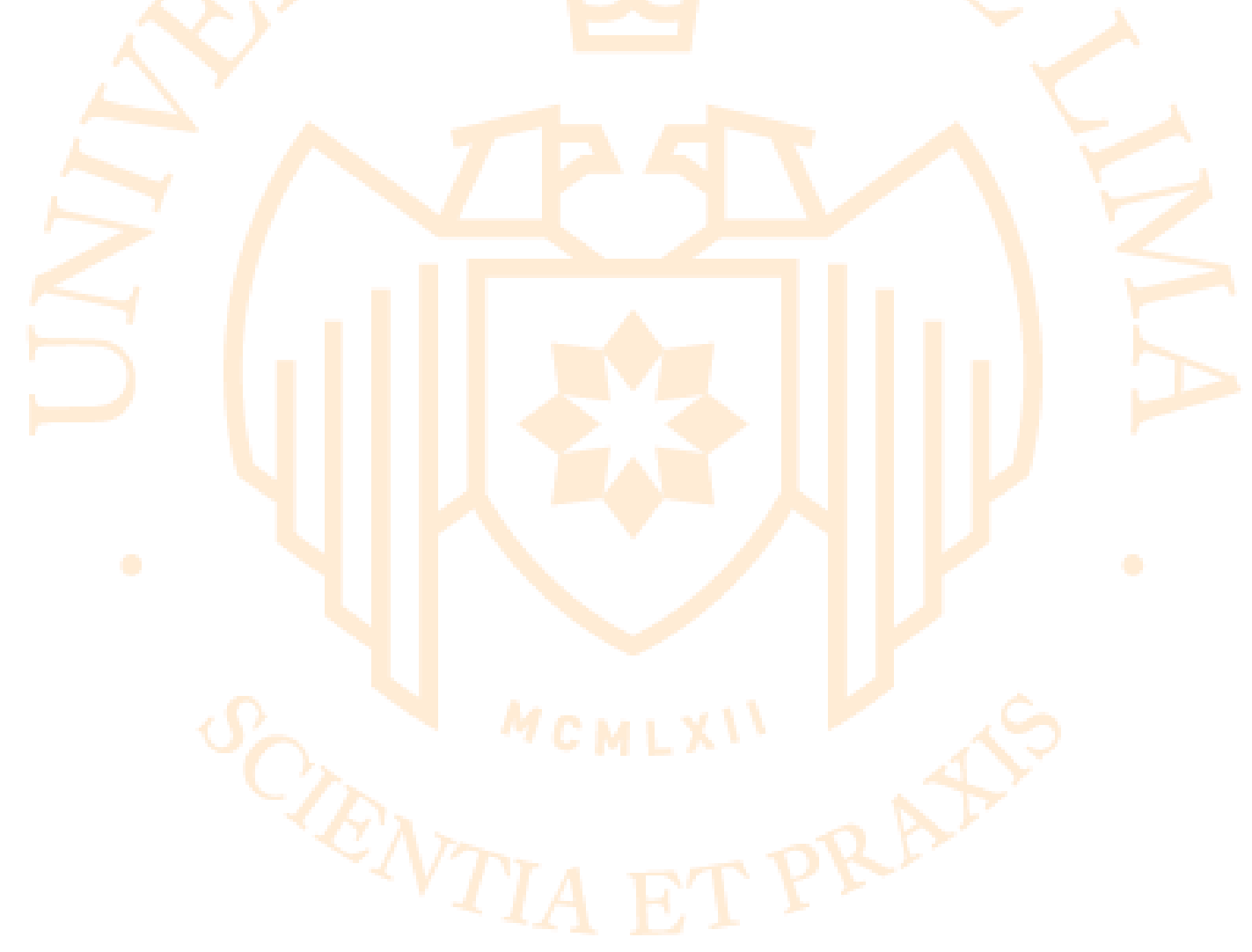




\section{Activos}

Activos corrientes

Efectivo y equivalentes de efectivo

Cuentas por cobrar comerciales y diversas,

Pagos a cuenta de impuesto a la ren

a la renta

Existencias, neto

Total activos corrientes

\begin{tabular}{|c|c|c|c|c|c|c|c|c|c|}
\hline 2018 & 2019 & 2020 & 2021 & 2022 & 2023 & 2024 & 2025 & 2026 & 2027 \\
\hline $\mathrm{S} /(000)$ & $\mathrm{S} /(000)$ & $\mathrm{S} /(000)$ & $\mathrm{S} /(000)$ & $\mathrm{S} /(000)$ & $\mathrm{S} /(000)$ & $\mathrm{S} /(000)$ & $\mathrm{S} /(000)$ & $\mathrm{S} /(000)$ & $\mathrm{S} /(000)$
\end{tabular}

Activos no corrientes

Cuentas por cobrar diversas a terceros, no corriente Gastos pagados por anticipado

Urosiones financieras disponibles para la vent

Propiedad plantas financieros

Intangibles

Activo por impuesto a la renta diferido

Otros activos

Total activos no corrientes

Total de activos

Pasivos y patrimonio

Pasivo corriente

Cuentas por pagar comerciales y diversas

Impuesto a las ganancias por pagar

Provisiones

Total pasivo corriente

Pasivo no corriente

Obligaciones financieras

Provisiones no corrientes

Pasivo por impuesto a la renta diferido

Total pasivos no corrientes

\section{Total de pasivos}

Patrimonio

Acciones de inversión

Acciones en tesorería

Capital adicional

Reserva legal

Otros resultados integrales acumulados Resultados acumulados Total Patrimonio

\begin{tabular}{rrrrrrrrrr} 
& & & & & & & & \\
89.906 & 96.918 & 104.478 & 112.627 & 121.412 & 130.882 & 141.091 & 152.096 & 163.959 & 176.748 \\
& 191.710 & 109.644 & 118.196 & 127.415 & 137.354 & 148.067 & 159.617 & 172.067 & 185.488 \\
94.351 & 40.821 & 44.005 & 47.437 & 55.138 & 55.126 & 59.426 & 64.061 & 69.058 & 74.445 \\
37.867 & 406.635 & 438.352 & 472.544 & 509.402 & 549.135 & 591.968 & 638.141 & 687.916 & 741.574 \\
377.212 & 6.452 & 6.956 & 7.498 & 8.083 & 8.714 & 9.393 & 10.126 & 10.916 & 11.767 \\
\hline 5.986 & $\mathbf{6 5 2 . 5 3 7}$ & $\mathbf{7 0 3 . 4 3 4}$ & $\mathbf{7 5 8 . 3 0 2}$ & $\mathbf{8 1 7 . 4 5 0}$ & $\mathbf{8 8 1 . 2 1 1}$ & $\mathbf{9 4 9 . 9 4 5}$ & $\mathbf{1 . 0 2 4 . 0 4 1}$ & $\mathbf{1 . 1 0 3 . 9 1 6}$ & $\mathbf{1 . 1 9 0 . 0 2 2}$ \\
\hline $\mathbf{6 0 5 . 3 2 1}$ & & & & & & & &
\end{tabular}

\begin{tabular}{|c|c|c|c|c|c|c|c|c|c|}
\hline 32.835 & 35.396 & 38.157 & 41.134 & 44.342 & 47.801 & 51.529 & 55.549 & 59.881 & 64.552 \\
\hline 999 & 1.077 & 1.161 & 1.251 & 1.349 & 1.454 & 1.567 & 1.690 & 1.822 & 1.964 \\
\hline 21.206 & 21.206 & 21.206 & 21.206 & 21.206 & 21.206 & 21.206 & 21.206 & 21.206 & 21.206 \\
\hline 489 & & 489 & & 489 & 489 & 489 & 489 & 489 & 489 \\
\hline $0.675,79$ & $1.960 .202,78$ & $1.846 .705,27$ & $1.739 .779,36$ & $1.639 .044,57$ & $1.844 .142,41$ & $1.937 .364,90$ & $1.825 .189,72$ & $1.719 .509,59$ & $1.619 .948,43$ \\
\hline 42.642 & 45.968 & 49.553 & 53.418 & 57.585 & 62.077 & $\begin{array}{r}06.919 \\
-\quad 6\end{array}$ & 72.138 & 77.765 & 83.831 \\
\hline 8.320 & 8.969 & 9.668 & 10.422 & 11.235 & 12.111 & 13.056 & 14.075 & 15.172 & 16.356 \\
\hline 214 & 214 & 214 & 214 & 214 & 214 & 214 & 214 & 214 & 214 \\
\hline 2.187 .380 & 2.073 .521 & 1.967 .154 & 1.867 .914 & 1.775 .465 & 1.989 .494 & 2.092 .345 & 1.990 .550 & 1.896 .059 & 1.808 .560 \\
\hline 2.792 .702 & 2.726 .058 & 2.670 .588 & 2.626 .216 & 2.592 .915 & 2.870 .705 & .042 .291 & 3.014 .591 & 2.999 .975 & 2.998 .582 \\
\hline
\end{tabular}

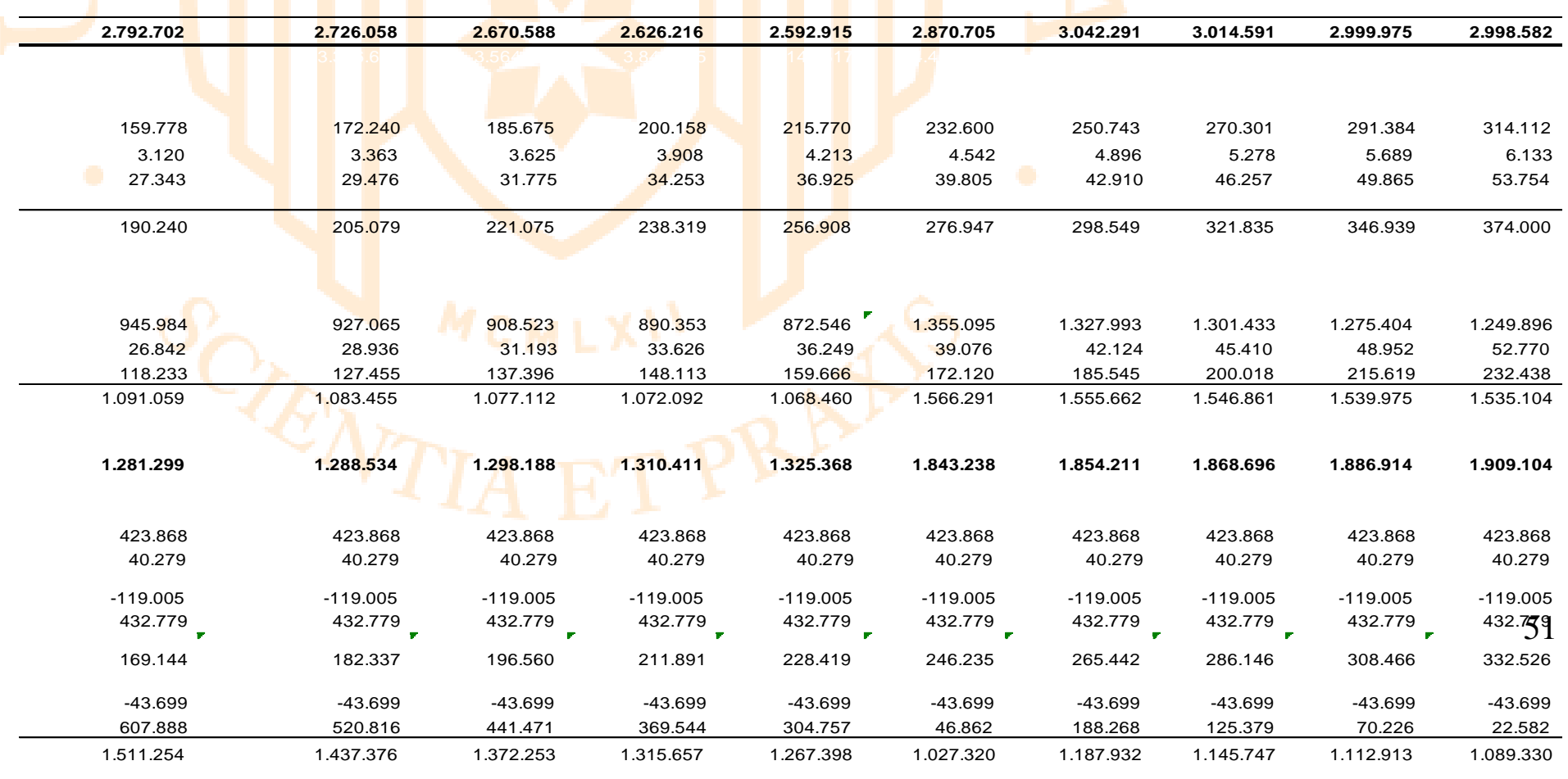




\section{Anexo 3: Proyección del Estado de Resultados del 2018 al}

\section{7}

Para realizar la proyección del Estado de Resultados del 2018 al 2027 se ha realizado la proyección de ventas en base al PBI del sector construcción (debido al proyecto "Reconstrucción con cambios" explicado en el anexo 1 y los demás proyectos explicados en el capítulo 1), luego se ha calculado el porcentaje de cada concepto en base a el promedio del análisis vertical de los años 2016 y 2017 (no se ha utilizado 2015 debido a que no se considera significativo, debido a que aún no se encontraba en funcionamiento la planta de Piura), en el caso de los gastos financieros se ha decidido mantenerlos como estables, debido a que se proyecta que la Compañía siga manejando bonos corporativos por la misma tasa cupón. 
Ventas

Costo de ventas

Utilidad bruta

Ingresos (gastos) operativos

Gastos administrativos

Gastos de comercialización y distribución

Deterioro de inversion en subsidiarias

Otros gastos operativos, neto

Total de ingresos (gastos), neto

Utilidad operativa

\section{Otros ingresos (gastos)}

Ingresos financieros

Gastos financieros

(Ganancia)Pérdida neta por diferencia en

cambio

Total de otros gastos, neto

Utilidad antes de impuesto a la renta

Impuesto a la renta

Utilidad neta de operaciones continuas

Perdida neta de operaciones discontinuas

Utilidad neta

\begin{tabular}{|c|c|c|c|c|c|c|c|c|c|}
\hline & 2019 & 2020 & 2021 & 2022 & 2023 & 2024 & 2025 & 2026 & 2027 \\
\hline $\begin{array}{r}2018 \\
S /(000)\end{array}$ & $\mathrm{S} /(000)$ & $S /(000)$ & $S /(000)$ & $\mathrm{S} /(000)$ & $S /(000)$ & $\mathrm{S} /(000)$ & $\mathrm{S} /(000)$ & $S /(000)$ & $S /(000)$ \\
\hline $1,335,947$ & $1,440,150$ & $1,552,482$ & $1,673,576$ & $1,804,115$ & $1,944,836$ & $2,096,533$ & $2,260,062$ & $2,436,347$ & $2,626,382$ \\
\hline$-796,167$ & $-858,268$ & $-925,213$ & $-997,379$ & $-1,075,175$ & $-1,159,039$ & $-1,249,444$ & $-1,346,900$ & $-1,451,959$ & $-1,565,211$ \\
\hline 539,780 & 581,882 & 627,269 & 676,196 & 728,940 & 785,797 & 847,089 & 913,162 & 984,389 & $1,061,171$ \\
\hline$-210,766$ & $-227,206$ & $-244,928$ & $-264,033$ & $-284,627$ & $-306,828$ & $-330,761$ & $-356,560$ & $-384,372$ & $-414,353$ \\
\hline$-46,869$ & $-50,525$ & $-54,466$ & $-58,714$ & $-63,294$ & $-68,231$ & $-73,553$ & $-79,290$ & $-85,475$ & $-92,142$ \\
\hline - & & & & & & & - & - & - \\
\hline$-1,058$ & $-1,141$ & $-1,230$ & $-1,326$ & $-1,429$ & $-1,540$ & $-1,661$ & $-1,790$ & $-1,930$ & $-2,080$ \\
\hline$-258,694$ & $-278,872$ & $-300,624$ & $-324,073$ & $-349,350$ & $-376,600$ & $-405,974$ & $-437,640$ & $-471,776$ & $-508,575$ \\
\hline 281,086 & 303,010 & 326,645 & 352,124 & 379,589 & 409,197 & 441,115 & 475,522 & 512,612 & 552,596 \\
\hline 4,929 & 5,313 & 5,728 & 6,175 & 6,656 & 7,176 & 7,735 & 8,339 & 8,989 & 9,690 \\
\hline$-73,759$ & $-73,759$ & $-73,759$ & $-73,759$ & $-73,759$ & $-73,759$ & $-73,759$ & $-73,759$ & $-73,759$ & $-73,759$ \\
\hline$-2,582$ & $-2,783$ & $-3,000$ & $-3,234$ & $-3,487$ & $-3,759$ & $-4,052$ & $-4,368$ & $-4,708$ & $-5,076$ \\
\hline$-71,412$ & $-71,229$ & $-71,031$ & $-70,819$ & $-70,589$ & $-70,342$ & $-70,075$ & $-69,788$ & $-69,478$ & $-69,145$ \\
\hline 209,674 & 231,782 & 255,614 & 281,305 & 309,000 & 338,855 & 371,039 & 405,733 & 443,134 & 483,451 \\
\hline$-67,982$ & $-73,285$ & $-79,001$ & $-85,163$ & $-91,806$ & $-98,967$ & $-106,686$ & $-115,007$ & $-123,978$ & $-133,648$ \\
\hline 141,692 & $=158,497$ & 176,613 & 196,142 & 217,194 & 239,889 & 264,353 & 290,726 & 319,156 & 349,803 \\
\hline
\end{tabular}

Fuente: Elaboración Propia

$141,692 \quad 158,497$

176,613

196,142

217,194

239,889

264,353

290,726

319,156

349,803 


\section{Anexo 4: Proyección de Necesidades Operativas de Fondos (NOF) desde el año 2018 al 2027}

Según Olieta (2012), para realizar la proyección de las Necesidades Operativas de Fondos (NOF) desde el año 2018 al 2027 se tomará en cuenta los siguientes conceptos: Existencias, Deudores (Cuentas por cobrar comerciales, Cuentas por cobrar con relacionadas), Pasivos (Cuentas por pagar comerciales, Cuentas por pagar con relacionadas y Otras cuentas por pagar a corto plazo) e Inventarios, y se realizará la proyección en base a un promedio del ratio de días promedios de cuentas por cobrar, inventarios y cuentas por pagar de los años 2015, 2016 y 2017. 


\begin{tabular}{|c|c|c|c|c|c|c|c|c|c|c|c|c|c|c|}
\hline & & & & & \multicolumn{10}{|c|}{ Proyectado } \\
\hline & 2015 & 2016 & 2017 & Pesos finales & 2018 & 2019 & 2020 & 2021 & 2022 & 2023 & 2024 & 2025 & 2026 & 2027 \\
\hline CxC Comerciales & 72,487 & 67,748 & 79,614 & $97.00 \%$ & 79,512 & 85,714 & 92,399 & 99,606 & 107,376 & 115,751 & 124,780 & 134,512 & 145,004 & 156,315 \\
\hline CXC Relacionadas & 1,771 & 2,676 & 2,463 & $3.00 \%$ & 2,460 & 2,652 & 2,859 & 3,081 & 3,322 & 3,581 & 3,860 & 4,161 & 4,486 & 4,836 \\
\hline Inventarios & 307,478 & 346,535 & 373,020 & $100.00 \%$ & 377,212 & 406,635 & 438,352 & 472,544 & 509,402 & 549,135 & 591,968 & 638,141 & 687,916 & 741,574 \\
\hline CXP Comerciales & 86,067 & 64,098 & 76,478 & $69.50 \%$ & 84,553 & 91,149 & 98,258 & 105,922 & 114,184 & 123,091 & 132,692 & 143,042 & 154,199 & 166,226 \\
\hline CXP Relacionadas & 6,329 & 5,406 & 5,773 & $5.25 \%$ & 6,383 & 6,880 & 7,417 & 7,996 & 8,619 & 9,292 & 10,016 & 10,798 & 11,640 & 12,548 \\
\hline Otras cxp corto plazo & 29,071 & 28,965 & 27,785 & $25.25 \%$ & 30,719 & 33,115 & 35,698 & 38,482 & 41,484 & 44,720 & 48,208 & 51,968 & 56,022 & 60,391 \\
\hline NOF & 260,269 & 318,490 & 345,061 & & 337,529 & 363,856 & 392,237 & 422,831 & 455,812 & 491,365 & 529,692 & 571,008 & 615,546 & 663,559 \\
\hline Variacion NOF & & $-58,221$ & $-26,571$ & & 7,532 & $-26,327$ & $-28,381$ & $-30,594$ & $-32,981$ & $-35,553$ & $-38,326$ & $-41,316$ & $-44,539$ & $-48,013$ \\
\hline Rotacion de CxC & $22^{\prime}$ & 21 & 24 & 22 & 22 & 22 & 22 & 22 & 22 & 22 & 22 & 22 & 22 & 22 \\
\hline Rotacion de inventarios & 161 & 172 & 186 & 173 & 173 & 173 & 173 & 173 & 173 & 173 & 173 & 173 & 173 & 173 \\
\hline Rotacion de cuentas por pagar & $64^{\prime}$ & 49 & 55 & 56 & 56 & 56 & 56 & 56 & 56 & 56 & 56 & 56 & 56 & 56 \\
\hline Ciclo de efectivo & 120 & 144 & 155 & $\overline{140}$ & 140 & 140 & 140 & 140 & 140 & 140 & 140 & 140 & 140 & 140 \\
\hline
\end{tabular}

Fuente: Elaboración propia 


\section{Anexo 5: Ratios Financieros Analizad}

Ratios de Liquidez

Capital de Trabajo

Ratio de liquidez

Ratio de Prueba acida

Ratio de Prueba defensiva

\section{Ratios de Solvencia}

Ratio de deuda

Ratio de endeudamiento total

Ratio de endeudamiento LP

Ratio de cobertura de Gastos Financieros

Ratios de rentabilidad

Margen Bruto

EBITDA
EBITDA / Ventas
2016

2015

$\begin{array}{rr}390,710 & 337,368 \\ 3.72 & 3.46 \\ 1.96 & 1.28\end{array}$

$\begin{array}{rr}1.96 & 1.28 \\ 70.42 \% & 31.38 \%\end{array}$

$70.42 \% \quad 31.38 \%$

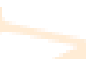

$39.95 \%$

$66.54 \%$

$59.15 \%$
9.10

$68.59 \%$

$7.34 \%$

$61.26 \%$

3.34

$-$

$49.61 \%$

315,370

315,370
$38.51 \%$

$43.74 \%$

284,076

$34.58 \%$
Variacion
(Dic 16 -Dic 2015)

$\%$

2017

$-53,342-13.65 \%$
-0.26

$-0.26 \quad-6.99 \%$

$-39.04 \%$

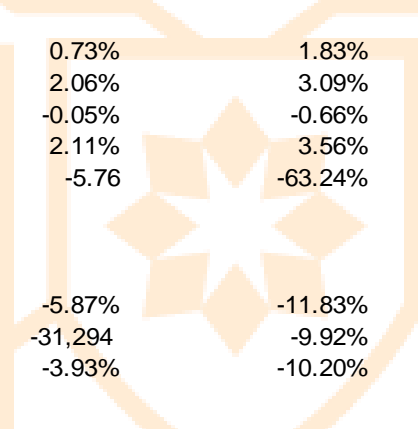

Ratio de endeudamiento CP

\section{Analisis DUPONT}

Ratio de rotacion de Activos

Rentabilidad sobre Activos (ROA)

$25.31 \% \quad 26.09 \%$

\begin{tabular}{ll}
$25.31 \%$ & $26.09 \%$ \\
\hline $2.32 \%$ & $14.14 \%$ \\
\hline
\end{tabular}

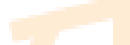

Multiplicador de apalancamiento financiero

Rentabilidad de Capital Propio (ROE)

\section{Ratios de conversion de efectivo}

Ratio de rotacion de Ctas $\times$ Cobrar Ratio de rotacion de existencias

Ratio de rotacion de Ctas $\times$ Paga

Ratio del ciclo del negocio

$\begin{array}{rr}52 & 36 \\ 223 & 236 \\ 108 & 91 \\ 167 & 182\end{array}$

$-4.06 \%$

$6.22 \%$

$+$

$\%$

36
236
91
82

$45.24 \%$

$82.61 \%$

$10.35 \%$

$72.26 \%$
2.59

Variacion
Dic 17 -Dic 1 $\%$

Formula

333,651

3.14
1.06

$18.49 \%$

$-3,717$

$\begin{array}{ll}-0.22 & -16.96 \% \text { (AC - Inv) / PC } \\ -2.89 \% & -41.08 \% \text { Efectivo / PC }\end{array}$

$\begin{aligned}-0.22 & -16.96 \% \text { (AC - Inv) / PC } \\ -12.89 \% & -41.08 \% \text { Efectivo / PC }\end{aligned}$

$1.24 \%$

$-43.92 \%$

$\begin{array}{rr}-16 & -43.98 \% \\ 13 & 5.49 \% \\ -17 & -18.92 \% \\ 14 & 7.90 \%\end{array}$

11

$\begin{array}{rll}43.97 \% & 0.23 \% & 0.53 \% \\ 292,515 & 8,439 & 2.97 \% \\ 35.85 \% & 1.26 \% & 3.65 \%\end{array}$

$0.53 \%$

$2.97 \%$
$11.19 \%$ AT / PT

20.43\% PT/PAT

$41.01 \%$ PC / PAT

$17.96 \%$ PL / PAT 


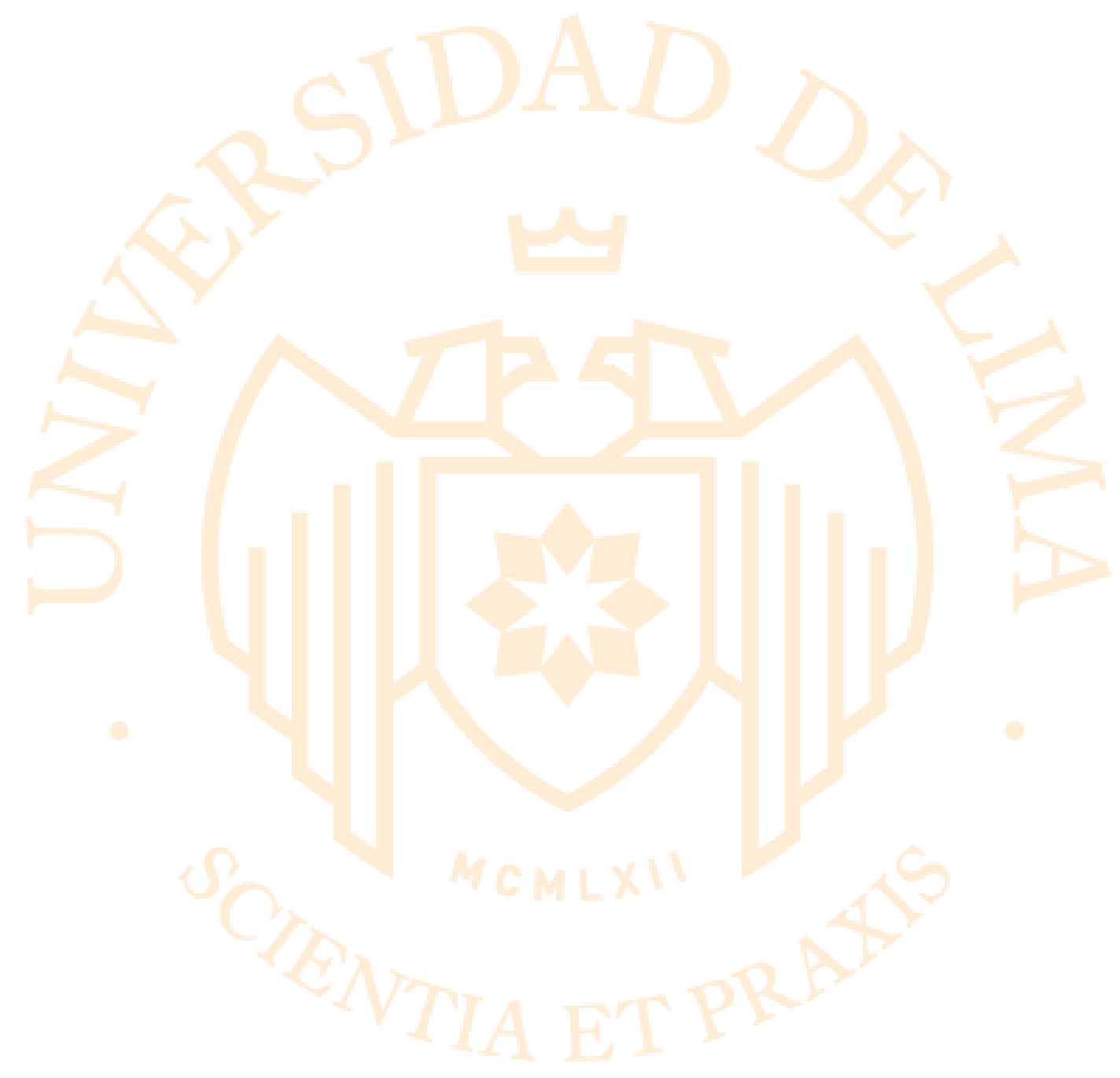

